\title{
S F 951 .546
}




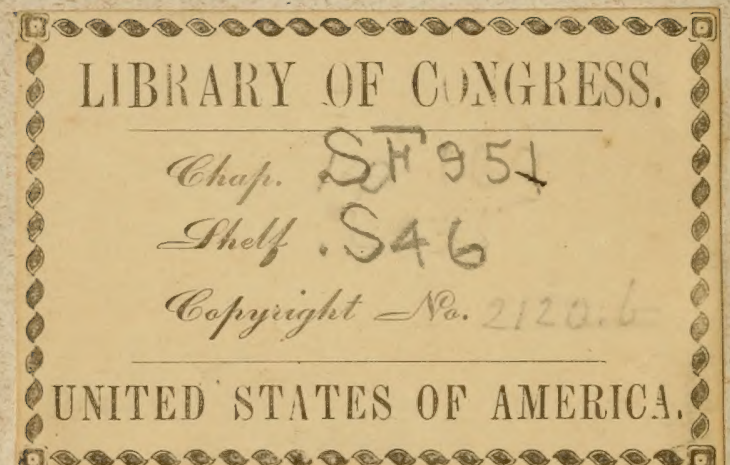

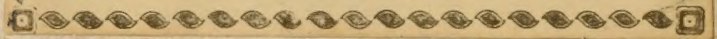






\section{AMERICAN HORSE DOCTOR,}

CONTAINING A DESCRIPTION OF THE

DIFFERENT DISEASES OF THE HORSE,

TOGETHER WITH THE

Latest and most Approved Mode of Treatment,

WRITTEN IN PLAIN LANGUAGE,

DESIGNED ESPECIALLY FOR HORSE OWNERS.

By Dx. D. J. SFLDEN,

VETERINARY SURGEON, MT. VERNON, 0.

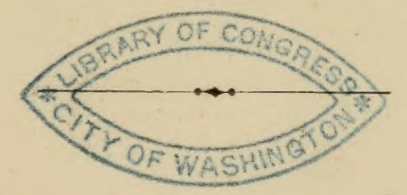

C L E V E L A N D :

FAIRBANKS, BENEDICT \& CO., PRINTERS, MERALI OFFICE. 1866 . 
Entered according to Act of Congress, in the year 1866, by DR. D. J. SHELDEN, In the Clerk's Office of the District Court of the United States, in and for the Northern District of Ohio. 
TO ALL OWNERS OF HORSES WHO HAVE BEEN LOOSERS BY MALPRACTICE OR IMPOSITIONS AT THE HANDS OF THE IGNORANT OR DESIGNING, THIS WORK IS RESPECTFULLY DEDICATED BY THE AUTHOR. 


\section{A D V ERTISEMENT.}

Since writing this book the Author has concluded to illustrate it by attaching a Chart containing about one hundred and forty cuts illustrating the different diseases. This chart has been obtained only at great expense, but by making this addition it will be the most complete and useful work for horse owners that has ever been published,

It is not designed to sell this book through the book stores or any of the many publishing houses. The only place that it can be obtained is of the Author. By enclosing Five Dollars in a letter and sending it to Dr. D. J. Seldex, at Mt. Vernon, Ohio, it will insure a copy by return mail. 


\section{P R E F A E .}

The AUthor of this work has been practising and teaching the Science of Doctoring Horses for more than thirteen years. With this extended experience he has become satisfied of the necessity of there being a more extended knowledg $\odot$ among horse owners with reference to the diseases of horses. In this country we have no Veterinary School, or at least none of any great repute, and but very few Veterinary Surgeons, consequently most owners of horses are obliged to do their own horse doctoring. Hence the necessity of a correct guide to be in the hands of every owner of horses There have been three different classes of Horse Doctor Books already issued in this country: One class is those really scientific works that are designed for the Veterinary Surgeon alone, as they are too complicated and written in too high language for the use of horse owners. Then there is a class of small receipe books that are really good, but they fail to give the requisite knowledge to make application of the receipes. Then there is a class that are written by men who have no knowledge about the diseases of horses, and only issue them to make money. No doubt but some scientific men, in perusing this book, may condemn it because it is in such plain language, if there are such homely phrases made use of to convey the ideas; or they may say that it does not contain enough, or that it should have shown more interest on the subject of anatomy. To the first objection I have to say that this work is designed especially for persons that have no 
medical education, and if they can understand it the educated certainly ought to. To the next objection I have simply to say that I think it contains all that is of use to the owners of horses; and to the last objection, it would be almost impossible to get most horse owners to read on the subject of anatomy, they considering it too dry and of but little use to them.

In compiling this work the Author has been careful to use such language as may be readily comprehended, and to give instructions that would be of the most use to horse owners. With this conviction he offers it to the public.

THE AUTHOR. 


\section{REVARKS AND EXPLANATIONS.}

Undoubtedly there is no subject in which owners of horses are more interested than the diseases of horses, and still there is no subject that is locked up in such ignorance and superstition. Even what are called our best horse men have no knowledge about the disease. They are mostly governed in their treatment by what they have learned of that most ignorant class, such as stage drivers and stallion groomers, and because they are widemouthed in self-praise of their knowledge in managing and doctoring horses, their words are considered by most of horse men as law and gospel. It seems to me that the simple matter of being a horse owner for many years, or having been among horses a long time is a poor recommend for a horse doctor. I think the only recommend that is of any account is the number of scientific works that the person has attentively studied, and the number of subjects that they dissected. I would much rather trust a sick horse in the hands of some good common-sense person, that had never been associated with these horse men, because his mind would 
be untrammeled by these superstitious and bigoted natives. I have always found that those that talk the most and make the greatest pretensions were really the most ignorant they attempt to make up in blow and bluster what they lack in knowledge. The better way for any person that has sick horses, if they have not confidence in their own ability, pay no attention to what every person that comes along may recommend, for if you do, it will be most sure to result in injury to the patient. It is truly astonishing with what readiness every person will prescribe for a sick horse, if they are not the owner; they are always willing to have experiments tried on their neighbors' horses but when they get a sick horse they are sure to call for advice, which shows at once that there is a want of confidence in themselves when their own property is at stake. I have cautioned all horse owners to beware of all such and take none of their advice. Do not be led into giving medicine when they tell you that it will do no harm if it does no good, or when they claim that they have cured some horse that was sick in the same way; for perhaps it was sick in the same way, but the chances are that it was not, for such persons are not capable of judging whether it was the same disease or not.

I will now give some plain advice which it will be well for every owner of horses to treasure up. 
When you are a'jout to examine a sick horse do not approach the horse, but stand off and notice his appearance, his position and motions and the appearance of the countenance, then obtain all that is possible about the history of the case from the person that has had the horse in charge. And here let me caution the practitioner to not take all that they may tell for truth, for oft times they will purposely deceive in order to have it correspond to their own notions or they may deceive through their ignorance, but believe only so much as looks reasonable. Be careful about expressing an opinion until you have made a thorough examination and are sure you are right. Do not be governed by what others may say, but make your own examination and rely entirely on your own judgment; form your judgment according to the symptoms, and when once formed do not alter your opinion unless there is some new symptom discovered. After noting the appearance of the horse, approach him in a gentle and kind manner, and notice the pulse, (the number of times per minute-the natural pulse is about thirty-six per minute), you feel the pulse by placing the fingers on the inner edges of the lower jaw-bone until you find a small artery about the size of a pipe stem. Not only notice the number of pulsations but the size of the artery, and whether it feels ridged and hard or whetber it is full and soft. A 
quick pulse denotes excitement or inflamation. A quick and hard or wirey pulse we find in inflamation of the bowels, and, also, some other diseases. A soft and not too full a pulse is considered a good symptom, as it shows that there is a free circulation. A slow but jerking pulse, together with coldness of the limbs, denotes congestion. A little practice in examining the pulse will be of great benefit to the practitioner. After noticing the pulse then look into the nostrils, and the color of nostril tells how the horse feels, as well as the color of a man's face indicates his feelings, then feel the limbs and ears; see whether they are cold or hot; listen to the sound of the lungs, by placing the ear upon the left side of the horse, just back of the forward leg, see if there is any unnatural sound; then place the hand against the bowels and press hard to see if there is any soreness of the bowels, in this way the practitioner may, by being careful, form an opinion what organs are aflected, then make up your mind what effect you want to produce on the patient and what medicine will be most likely to produce that effect, and give the required dose, and be sure and give it time to produce an effect before giving more. It is not expected that the practitioner will always use just exactly the medicine that is recommended in this book, but use something that will produce the same effect, and when you are in doubt go to your 
nearest physician and consult him about it, as thediseases of horses and men are almost exactly alike and want doctoring with the same medicines, using twelve times as much as you would for a man. Be sure you never give medicine until you are sure what is ihe matter and what effect you want to. produce and then do not give over doses, thinking that if a little is good more is better, for some. medicines, when you give over doses, will create. the very disease which you are trying to destroy. And finally, good common-sense is about all that. is required to treat most of cases successfully. 


\title{
TIE AMERICAN HORSE DOCTOR.
}

\author{
CHAPTER I. \\ DISEASES OF THE BRAIN. \\ INELAMMATION CF THE BRAIN.
}

The real cause of this disease is unknown, but probaly arises from over exertion or exercising on a fuli stomach. The symptoms are that the horse will be dull and stupid for a few hours or days, then will become wild and furious, is apparantly crazy, the countenance will have a wild expression, perhaps beat and thump around in a fearful manner, perhaps get the breast against a beam or fence and stand and pull with all his strength, or may run in a circle.

The treatment is first, bleed from the neck, from one quart to one gallon, or until the horse seems to be easier, then bind cloths on the head wet with cold water and change them often so as to be sure to keep them cold; give $1 \frac{1}{2}$ pints of linseed oil in a drench or any kind of physic that may be most handy; repeat the physic every 


\section{3}

12 or 15 hours until it operates, and in the meantime give the following. I oz. tincture of lobelia, $\frac{1}{4}$ oz. tinct. of opium, every hour until better. This is a fearful disease and usually results in death, and many times in a few hours, but the above treatment is all that can be done.

\section{BLIND STAGGERS.}

Cause, over feeding and over exertion on a full stomach.

Symptoms. - The horse is usually taken suddenly, while driving, with a staggering gait, does not mind the rein, perhaps falls, and while down struggles and keeps the limbs moving as though still traveling.

Theatment.-Bleed from the neck vein until somewhat better, then give a strong dose of any kind of physic that may be most handy, and give Tincture of Lobelia 1 oz. at a dose every hour until better, then a run at grass for a few weeks if convenient; if not give the cleansing powders every day for two or three weeks, and it will probably not return again if it is the first attack. But if the horse has had more than one attack there is no chance for a cure, and it may return at almost any time, and without any apparent cause. The attacks becoming more frequent until at some time they result in death. Such a horse is dangerous to drive and of kut little value. There are other diseases of the brain, snch as 


\section{4}

Megins, Appolexy; Vertigo, Concussion of the Brain, Lethargy, \&c., \&c., which it is not necessary to discribe in a work of this size, and it is of no practical benefit to the horse owner; for in all Brain diseases there is so much similarity to what has already been said, and the treatment be. ing about the same and fully laid down, the author does not deem it best to bewilder the horse owner with mere technicalities.

\section{HYDROPHOBIA OR MADNESS,}

This is caused by the bite of some rabid animal and usually demonstrates itself within six weeks after the bite; but it is stated by some authors that the poison may remain dormant in the system for a year before it results in apparent injury.

Symptoms.-This seems to be almost entirely a nervous disease, and first the horse will commence licking his skin with wonderful energy in different places, which seems to itch intolerably; the appetite is always affected; sometimes there will be but little appetite, then again he will eat every thing before him even to the most filthy, or dry and hard substances. Sometimes he may drink large quantities of water, then again the sight of water may cause spasms. Then he will have regular spasms, frothing at the mouth and biting at any article that may be in his way. The spasms becoming more frequent, until death ends the suffering. Whenever there is surpicion 
that a horse has been bitten by a rabid animal or shows symptoms of madness he should be put into a strong stable by himself, and as few people allowed to go near him as possible until the case is clearly made out, and if it is a case of hydrophobia the humane man would cause the horse to be shot or put to death immediately, in some way, so as to end his misery, as there is no possible chance for him to recover.

\section{TETANUS, OR LOCK-JAW}

Is caused, usually, by some injury, such as a prick from a nail, or knife, or any sharp instrument penetrating or injuring some nerve, or it may be caused by being out in a cold storm or a sudden draught of air, and many other causes that will effect the nerrous system.

Symptoms. - The tail is elevated, the ears pointed forward, the head raised, the legs stiffened and stretched out, and the jaws tightly locked; the membrane in the inner corners of the eye is drawn backward so as to partly cover the sight of the eye; which shows clearly that it is a case of lock-jaw.

Treatment.-Place the animal in a solitary stab!e and allow no person to go near him but the one that he is most acquainted with, first having given him a large dose of physiz, place a bucket of water and some food within reach, and leave 
him alone, only going often enough to change the food and water, and if the disease lasts so long that there is danger of the horse starving, life may be sustained by introducing a tube of gutta percha or some soft substance into the nostril ard inject with a syringe through the tube a sufficient quantity of corn meal gruel to sustain life.

This disease scarcely ever lasts more than four or five days, and everything depends on keeping the horse entirely quiet, free from even the smallest cause of excitement, and getting the bowels open and keeping them loose. It would also be of service if you could get some Tincture of Lobelia. down him in some way. Say 1 oz. every hour in $\frac{1}{2}$ pint of water.

PARALYSIS, PARTIAL OR COMPLETE.

This is a difficulty of the spinal nerve, caused by a strain, taking cold, or some undue exer. cise or exertion, and may come on very sudden, and is often times mistaken for a difficulty of the kidney, or strain across the loin. It is tn be remembered that all motion is controlled by the nerves, which originate in the brain, and pass out through the first bone of the neck, (except the optic nerve of the eye, ) and along the back, branching out in different directions to every part of the system. Conseruently, when there is an injury to this spiral nerve, all of the 
system back of the injury is paralysed just in proportion to the amount of injury. Complete paralysis is when the nerve is so badly injured that the animal looses the entire use of the part which lays back or beyond it. Partial paralysis is when the injury is so slight as not to loose all motion. In some cases it will only affect one limb or one side, or only the hinder parts, or nearly the whole system may be affected. When it is the hind part that is affected, most persons think that it is a strain across the loin and consequently will subject the horse to much suffering by applying blisters or stimulating medicines to the loins. This kind of treatment is entirely useless in paralysis and, I think, injurious. If it is possible to determine the exact location of the injury it is best to apply some cooling application, like salt and water, or something to subdue inflammation, keep the bowels loose by giving bran mashes, and, if necessary, some mild physic, like linseed oil, say 1 pint at a dose, just to keep the bowels open; then give strychnine, half grain at a dose, twice per day, made into a pill by mixing flour with it and increase it gradually, so that in six weeks to have it so worked up to one grain and a half at a dose and leave the rest to nature. This is a lingering complaint and when they get well, it takes many months, for there is little that can be done with medicine. 


\section{CHAPTER II. DISEASES OF THE EYE.}

Most of the writers on the Horse have divided the Diseases of the Eye into a number of different classes. That is all well enough for the scientific practitioner, but in this country where we have no Veterinary Schools, or at least none that have acquired any reputation, we have so very few really scientific practitioners, that most of the horse owners have, of necessity, to be their own horse doctors, and as this book is designed for the horse owners instead of Veterinary Surgeons, it would be the greatest of folly for me to give a detailed description of all the different diseases when the treatment is the same in all. It matters not what disease it is that ails the eye, the principle is to reduce inflammation and to strengthen the eye. This, in slight cases, may usually be done by the application of cold water, which should be applied by bathing the eye at least every half hour during the day time, each day, until the inflammation has entirely subsided. Then bathe it three or four times per day for two or three weeks until it has had time to gain strength. If this 
should fail, use the following wash: 2 graing of sugar of lead, 1 grain sulphate of zinc, 1 dram tinct. of opium, 1 dram tinct. of arnica, 2 oz. soft water. This should be applied three times per day by putting a twitch on the nose, then put the nose or mouth of the phial in to the eye, being careful that the phial is perfectly smooth, and tip it up, letting the medicine run in. The eye will clear up in three or four days and look much better; then reduce the medicine by adding water, and continue to use it for two or three weeks after it looks entirely well, so as to gain strength. If the disease still proves stubborn, give the cleansing powder for two weels, put a rowel into the cheek below the eye and continue the wash. If this all fail there is but. little chance for a cure. Do not use any of those harsh and cruel medicines which are so frequently used, for the horse's eye is as tender as your own. 


\section{OHAPTER III.}

THE MOUTH.

\section{LAMPERS}

Is supposed by most horse owners to be a very troublesome complaint among young horses, and ignorance has caused much cruelty to be practised on that noble animal for a purely imaginary complaint. I have been practising for near fourteen years and have never seen a case of lampers. It is natural for the gums of the upper portion of the mouth in all young horses to protrude or drop below the teeth, some more than others, and they do no harm. If the horse should have the lampers, the gums would be as red as scarlet with inflammation, and then I think that burning, which is so much in practice, would be a very barbarous way to reduce inflammation. In most cases when horses are supposed to have the lampers the difficulty is in the back part of the mouth, for the colt at three years old cuts eight grinders, or molar teeth, and the same at four years old. With some young horses they are very sore, and, consequently, it is difficult for the horse to feed, but let it alone and it will all come right, but if 
iguorance or superstition still prompts you to do something for an imaginary complaint, I think a little scarifying, or cutting the gums, should satisfy you, and the less the better.

I might here say that a horse scratching the tail against the side of the barn or stall has nothing to do with the mouth, but take a little saleratus water and wash the tail two or three times and it will end the difficulty.

\section{CANKER, OR SORE MOUTH.}

These are small ulcers or canker sores forming on the mouth and tongue, with inflammation and sometimes swelled lips. Others make several different diseases of sore mouth, but I shall include it all in one, so as not to confuse the owner. Wash the mouth two or three times a day with the following wash: Borax 5 oz., sage tea 1 gallon, honey or molasses 1 quart. After it has cooled hold the horse's head up and pour half a pint into the mouth; after a moment let the head down and allow the wash to run out. Keep the bowels open by soft food, and do not permit the horse to be worked until the disease has entirely disappeared. If it proves stubborn, give the cleansing powders for a week or more, to cleanse the blood. In all cases of injury to the tongue or lips by the bit or other means, treat the same as any other injury, as will be explained in the proper place. 


\section{CIAPTER IV. THE NOSTRILS.}

\section{NASAL GLEET,}

Is a discharge from the nostrils; sometimes only one nostril, but more commonly both are affected. The discharge will vary in color and quantity, sometimes being nearly white, at other times being yellow or even a dark brown. It usually has no bad smell, but in bad cases the discharge has a very bad smell. It does not seem to affect the general health of the horse but if bad, he will run down and loose flesh unless well cared for. This disease is not contagious and I do not think there is any danger of its terminating in glanders, it is caused by exposure or the result of distemper, or it may result from a blow or injury to the head.

Ticatment.-Let the horse have rest; take of allum $\frac{1}{2}$ lb., rcsin $\frac{1}{2}$ lb., blue vitrol $\frac{1}{2} \mathrm{lb}$, ginger $\frac{1}{2} \mathrm{lb}$. Mix all well together, and give a table spoonful twice per day, being careful to keep the bowels loose by giving bran mashes, or green feed. It will take some time to complete a cure, 
but do not get discouraged but continue the medicine.

\section{NASAL POLYPUS,}

Is a pendulous sack which forms in the nostril and only attached to the membrane lining of the nose at the upper end, and hanging down in the nostril and becomes so large as to obstruct the breathing, for it is to be remembered that a horse cannot breathe through the mouth. The only cure is to take a zinc wire and bend it in such a shape as to work it up above the sack to the neck or small part, and draw it tight around it and leave it, and it will slough off in a few days. There is an instrument made in somewhat the form of a crooked pair of shears that is used to separate the sack from the membrane, but it is difficult to obtain them, so the best means usually at hand is to use the wire. Often times it will grow in again; if so remove it in the same way. 


\section{CHAPTER V. THE THROAT.}

SORE THROAT.

This disease seems to be contagious for when it once gets into a stable most of the horses in the stable are apt to have it, and through the neighborhood. The first perhaps that would be noticed is a dry hacking cough, and within a few days a difficuity of swallowing, which will continue to get worse and worse, until it is with the greatest of difficulty that the horse can swallow water, and within a few days there will be a copious discharge of matter from the nostrils, and perhaps the mouth, and in a few days the horse will recover. There is usually no swelling on the outside of the throat, but in a few cases I have seen the glands swell similar to distemper, but there will be much more soreness on the inside of the throat; the horse will seem to be much weaker, and experience greater difficulty of swallowing than with distemper.

Treatment.-When the horse is taken sick put him in some place where he can have plenty of pure air to breathe, give only soft moist food or 
gruel to drink. Give no Medicine unless there is great difficulty of breathing, if there is put a poultice of common brown sugar and bar soap, equal parts moistened with water on to the throat by means of a bandage about six inches wide, long enough to come under the throat and over the head to tie; tear into each end in three places, so as to make four tails to it; bring it up over the head, and tie two of these tails together in front of the ears and two back of the ears, and it will then keep its place and hold the poultice. Leave this on, keeping it moist, until the discharge is running freely from the nose, and if there is great difficulty of breathing it is a good plan to build a small fire and put a little tar or old leather on it; then put a blanket over the horse's head, and hold his nose over the smoke, making him breathe as much of it as possible without strangling, and continue this for several hours, or until the horse breathes more free, or the discharge is free from the nostril. In most cases of this kind of sore throat, it is not necessary to use any medicine. They get along without anything. The danger seems to be of the inflammation in the throat becoming so great as to close the air pas. sage. Consequently all that is needed to be done is to get the discharge from the nostrils started, and the inflammation will soon subside. They are usually sick a week or two, and are apt to have a 
cough for sometime afterward. If they do not seem to thrive after recovery, or the cough is bad, or ulcers break out afterwards in any part of the body, it is because the blood needs cleansing, consequently give the cleansing powders for a week or two.

\section{COUGH.}

This may be caused by an irritation of the lungs or membrane lining of the wind pipe, or an irritation of the ripper portion of the wind pipe, what is called the larynx, which gives it the name of Laryngitus, and it may originate from a difficulty of the Bronchial tubes. It is very dificult for an inexperienced person to determine the exact location of the difficulty that causes the cough, so I think the best way would be to treat it on general principles. Take a tea-spoonful of powdered lobelia and mix it with a bandful of salt, and throw it into the feed box every day, and the horse will lick it up; and if this does not do, give the cleansing powder so as to regulate the wholesystem, and give the following twice a day on the food: from ten to twenty drops Oil of Tar, Balsam of Copaiba, Tincture of Capsicum, and Turpentine, equal parts.

\section{CHOKING.}

When there is any foreign substance lodges in: the Esophagus or what is commonlv called the 
gullet, there is no danger of it causing immediate death. In some cases it may be detected by feeling with the hand on the outside; if so, it can generally be worked in a downward direction with the hands, but if you can't find it with the hand or cannot remove it, get a smooth round stick like a whip stalk that will bend, and make a wad of tow or cloth on the end, and tip the head up, and introduce the stick down the throat; and by gentle pressure force the substance down into the stomach. I have known horses to be choked on oats and to have the choke continue for six or seven days, and finally get well without any assistance. 


\section{CHAPTER VI. DISEASE OF THE CHEST.}

\section{LUNG FEVER.}

With most of authors on horse diseases they give a lengthy description of the different diseases of the chest, such as congestion in the field, congestion in the stable, Bronchitis or inflammation of the air passages, Plurisy and Pluri Pneumonia, all of which is either congestion or inflammation of some of the different organs of the chest, and the treatment being the same with each of the organs, I do not deem it best to bewilder the horse owner by these nice destinctions, which is all right for the scientific practitioners, but would be likely only to lead the inexperienced into error. I shall proceed to describe the symptoms (as they are nearly the same with each of the foregoing diseases,) and the treatment which has universally proved successful with me.

Symptoms. - These diseases usually commence by a chill or shivering fit, and the horse will stand back at the end of the halter, head down and breathing hard, legs rather braced out as though afraid of falling; wiil make no motion more than 
to occasionally turn his head slowly around to his side, his legs will be cold, his ears cold and nose cold, the membrane of the nostril will have a very pale and sickly appearance. This is the congested stage; congestion of some of the organs of the chest. Now the object would be to cause the system to react, for the blood vessels of the congested organ are over-charged with blood, while there is not enough blood in the extremities or limbs, which causes the coldness. Now our object should be to equalize the blood to get it to circulate all through the system as near alike as possible. This we do by rubbing the parts that are cold so as to draw the blood to them and relieve the congested organ or organs where there is too much blood. The horse should be well covered with blankets and his legs thoroughly rubbed with the naked hands or hay wisps by at least two persons at a time, or washed with hot red pepper tea or even warm water as warm as the hands will bear, and continue to rub and apply warm applications to the limbs until they get warm and the chill has passed off. I have attented many cases where this treatment alone actively applied has thrown the disease off entirely. But if the congestion is not relieved soon inflammation will follow. If inflammation sets in you can readily tell by the appearance of the skin or membrane lining of the nose assuming a red or scarlet appearance, the 
legs will be hot, breath hot, tongue parched and dry, the pulse being full and quick, (the natural pulse is about thirty-six pulsations a minute.) If you cannot readily find the pulse, note the beating of the heart (which would be the same) place your ear down on the horses right side, just back of the forward leg, and listen carefully and you will discover an unnatural grating or harsh sound of the lungs, which you would readily detect by comparing with a well horse, and then the great symptom is that with any of these diseases the horse never lies down until death occurs or the disease has left him. The trouble now is that the whole system has become contracted, or at least the blood vessels which cause the quick, hard beating of the heart in its effort to force the blood through the vessels, and forcing the blood through the contracted vessels produces friction, which causes the unnatural beat.

Now our object should be to relax the whole system so as to enlarge the blood vessels and stop the friction, and so lessen the fever. This we do by giving repeated doses of anything that will make the horse sick at the stomach; I generally use tincture of lobelia, giving it in 1 ounce doses, mixing with water, every hour, until I have got the pulse or the beating of the heart down to at least fifty per minute; then give the doses as would be necessary to keep it down, and 
as long as you can control the action of the heart, the patient is doing well enough, and will recover. In bad cases, it is well to blister the chest, and back of each of the forward legs, by rubbing in the following prescription: 2 oz. turpentine, 2 oz. tincture of Spanish fly, 2 oz. aqua amonia, 1 oz. oil organum. Mix all together, and rub in with the hand every hour until it blisters. If it is not convenient to get tincture of lobelia, go to your nearest physician and get of him the same kind of medicine that he would give to the human subject, using from eight to twelve times the quantity and use it the same, and treat the disease as near as though it was a man as possible. But be very careful and not give any powerful physic, for with the horse, there is that sympathy existing between the chest and bowels, that to give physic with any of these diseases of the chest would most likely bring on inflammation of the bowels, which would be most certain to result in death. This is a disease that sometimes will result in death in seventeen hours, but more frequently lasts for several days, and even weeks; and when they recover, it is usually slow. I used to follow the old fashioned treatment of bleeding and blistering for this disease, and used to lose many patients; but since I have adopted the above treatment I have never lost a patient where I lave had the management from the com- 
mencement. I neglected to notice that the bowels should be moved two or three times per day by giving injections up the rectum with a large syringe, of soapy warm water. Inject a quart at a time, and repeat every half hour until there is a passage. It is best for the horse owner to bear in mind that whenever a horse has a chill, there is great danger of lung fever, and consequently it needs immediate and constant attention. Do not give any whiskey and pepper or any of those stimulating medicines that are often pressribed by the ignorant, for in many cases, the stimulating medicines bring on inflammation when otherwise it might pass off without further diffculty ; and after inflammation has once set in, all that is needed is to control the action of the heart. Do not pay any attention to what others may say who are so free to give advice without fee or reward. Remember that advice about diseases in men or horses, that is good, comes only from thcse that obtained their knowledge by hard study, and they value it too highly to voluntarily give it away.

\section{DROPSY OF THE CHEST.}

This is usually the result of pleurisy or lung fever, or of bad treatment in either disease. This is easily detected by the sound of the lungs. Place the ear low down on the side and your will 


\section{3}

hear no sound; but back and high up you may hear the lungs, which will have a dull, heavy sound. Keep your ear against the horse while some one slaps the horse with the flat of the hand on the opposite side, and you will hear the sound of the water. There is but very little prospect of a cure. The only chance would be to tap the chest, and you would have to employ a Veterinary Surgeon, in order to get the proper instruments to do with, and the chances of a cure would be so slim that it would not pay to be to so much trouble about it.

\section{HEART DISEASE.}

This is not an uncommon disease among horses, and it is very difficult, even for a practical Veterinary Surgeon to detect heart disease on the living subject, and if we could, it would be a matter of small importance, for there is no cure, and is certain to result in death, and that very sudden. The horse may appear well and even lively, and the next instant fall dead. Many cases where horses have died suddenly with this disease, after a post mortem examination by inexperienced persons, they have pronounced it Botts. The scientific man could have readily told that it was heart disease. 


\section{CHAPTER VII.}

\section{DISEASES OF THE STOMACH.}

ACL'TE INFLAMMATION OF THE STOMACH.

This disease is usually caused by some poisonous drug which has been given to the horse, and the symptoms depend almost entirely upon the kind of poison that has been given; and if it is not certainly known that poison has been given you had better treat it as a case of cholic, for the symptoms will be nearly the same, and so with the treatment. But if it is known that poison has been given, then you give a pint of any kind of soft oil that might be at hand, and if not rerelieved in twenty minutes, give the following: $1 \frac{1}{2} \mathrm{oz}$. tincture of opium, $1_{2}^{1} \mathrm{oz}$. sulphuric ether,

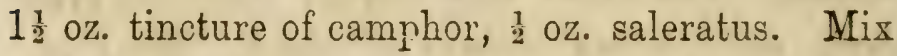
with one pint of water, and if not better in $\frac{1}{2}$ hour, repeat.

CHRONIC INFLAMMATION OF THE STOMACH.

This disease is brought on by some derangement of the stomach. Bad food, standing in filthly stables are very common causes, and are 
most common at the age of five or six years. The symptoms vary with different subjects. There is always a deranged appetite. Perhaps the animal will not taste food at all, or may eat everything before him, or may refuse good clean food, and still eat the most filthy; may gnaw old pieces of bricks, mortar, or clay ground, with seeming good appetite; may have a sudden attack of scours, and as suddenly stop altogether and be troubled with costiveness. The dung will be dry and hard and easily crumbled when pressed upon. A dry cough may be present. The membranes of the nose and mouth have a pale appearance, the mouth is cold, and they soon lose flesh and become mere skeletons. I should commence the treatment by giving $\frac{1}{2} \mathrm{oz}$. of saleratus dissolved in water, and repeat this once in every three or four days, and in the mean time, give the following powders: Pulverized blood root, 2 oz., gentian pulverized, 2 oz., ginger 4 oz., calomel $\frac{1}{2}$ oz. Mix all together and give a table spoonful twice a day in the feed, being careful to keep the bowels open by giving green or soft food, and if necessary, give a dose of linseed oil, one pint at a time. If the bowels are too loose, give the following: $1 \mathrm{oz}$. tincture of opium, 1 oz. tincture of camphor, 1 oz. tincture of capsicum, 1 oz. tincture rhubarb. Mix all together, and give one half in $\frac{1}{2}$ pint of water. 


\section{6}

If not better in one hour, give the balance, and so continue the medicine as the symptoms may. indicate.

\section{CRIB BITING OR WIND SUCKING}

Is by some considered as a disease, and by others a habit. Some contend that the habit is caused by a sourness of the stomach; some contend that it is a habit learned by standing beside a cribber, or idleness, while others claim that it is learned while cutting teeth, the itching sensation of the gums causing the horse to bite on the manger, and learns the habit of cribbing. It is my opinion that all of these causes may produce the difficulty or habit, but I believe that all have failed to find a cure. I think the best way to manage a cribber, is to keep him in a smooth stall, without manger, and suspend a basket by a rope to feed him, there being nothing to get his teeth on to he could not crib. Then when you take him out, have the throat strap of the bridle made of thick leather and put some brads through it, so that when he attempts to crib, the glands of the neck fulls or swells out, and would fill the strap and cause the brads to stick him and cause him to let go.

\section{BOTS.}

Bots are a small grub or worm about threefourths of an inch long, of a brownish cast and 
rough skin, that are attached or stuck into the inner or cuticules coating of the stomach of most horses that are kept in the country, but in large cities we frequently find horses without any Bots in the stomach, which shows that they are not necessary to the existence of the horse. They are also frequently found in the stomach of cows, oxen, sheep and dogs, and even in some cases in the human subject. They are said to originate from the eggs or larvæ of the gad-Hy that we so frequently see so busy in depositing their eggs on the hairs of the legs, shoulders and about the head. These eggs, by some means, probably by the horse licking the part and the hair adhering to the tongue, and by that means get into the stomach and then form the bot and remain attached or stuck into the walls of the stomach until the following spring, when having got their growth, let go and pass off through the alimentary canal, and after a short time are changed from a bot to a fly, when the female becomes pregnant and lays the eggs as before. It has never been determined why these bots are in the stomach, as they do no good, and it is my opinion, and I believe that it is the opinion of all Veterinary Surgeons of the present day they do no injury, or at least never cause sudden sickness or death. I am. well aware that I shall meet with strong opposition on this point by ignorant men, or men who 
have failed to reason on this subject. In writing these pages I do not intend to pamper to the prejudices or superstitions that have been handed down from generation to generation, since the days of witchcraft to the present, but to give to the public the benefit of my experince and reas. onings, and more especially on the subject of bots, thereby washing my hands of, and being no longer accessory to the murders that are so frequently committed on that most noble of all animals the Horse. In the manner of bots, only to think of the mal-practice, ignorance and superstition that have been covered up by that wonderful and entirely imaginary disease callerl Bots.

I will now give some of the reasons why I think bots never cause sickness or death of horses. First, that they do not choke a horse to death, because they cannot get into the wind pipe, and to clog the esophagus or gullet would not stop the breathing or effect any of the vital organs that would result in death until inflammation should set in and extend to the vitals, which would take several days. That they do not eat or knaw the stomach, because the mouth of the bot is so formed that it would be impossible, and while the stomach is in a healthy condition the little animal is too comfortably situated to atternpt to destroy its own habitation, and when the stomach becomes diseased so that it becomes disagreeable 
it would hardly be supposed that it would fall to work and eat large quantities of that which it was trying to escape from, and if they should eat the stomach so as to cause death there certainly would be marks of violence, such as would be plain for any man to see of blood spilled and lacerated internal organs, until following the march of these infuriated insects they had passed through the strong and thick walls of the stomach and to attack upon the diaphragm or midrif, that strong wall which nature has placed to guard the entrance to the vitals by way of the stomach, and have destroyed this wall, and have seized upon the vitals of their victim, and have wounded or pierced the heart or lungs, and have finally accomplished their murderous designs. This may look like an overdrawn picture, but stop and reason. Is it not all true that for bots to cause death they must effect some of the vital organs, and the only way they could accomplish this would be by a direct attack, or by producing inftammation of the stomach that would extend into. the vitals, which would take from four to twelve. days to accomplish after the attack upon the stomach. But you must remember that there never was a case where bots was through the stomach and the stomach was inflamed. Now' unless you find that there has been a direct attack upon the vitals or that the injury to the stomach 
has produced inflammation, and that extended to the vitals to cause death. You have no evidence that bots kill horses. Suppose that bots should penetrate the stomach, every sane man must know that would not produce death without inflammation any more than the same injury would to the skin of the horse. A man would live with a hole shot through the stomach from four to twelve days, and in many cases have got well. Then why is it that the injury of a few bots to a horse's stom. ach should cause almost instant death; and why is it that bots only practice their murderous designs on the horse when they are found so frequently in the stomach of other animals; and why is it that if sage tea, milk and molasses, or any other of the humbug remedies for this imaginary disease, will cause the bots to quit their murderous designs, and to heal the stomach of the injury that has already been done, and prevent inflammation from following the injury in so short a space of time, as we are told that it will. Why would it not heal a bullet wound, or a wound produced by other means, in the same length of time? The reason why men have run into these errors is because they have believed that the same appearance which they find in a dead subject would appear in the live one. They do rot stop to consider that the gastric fluid in a horse's stomach might destroy the strength of the stomach with. 
out altering the appearance in twenty minutes after death, so that there is but little to hinder the bot from working through; even a slight motion to work a hole through; and that when they find them in either the upper or lower passages, congregated in quantities, or through the stomach, that they are merely attempting to save their own lives by escaping from the dead carcas, where it is certain death to remain. Now I hope that the horse owner, after perusing the foregoing, will no longer torture the sick horse by giving these great bot remedies, or subject themselves to the loss of their valuable property by doctoring for an imaginary disease, while the horse is dying with something else. It is usualiy colic or inflammation of the bowels that ails horses that are supposed to have the bots. See article on Colic. 


\section{CHAPTER VIII.}

\section{THE BOWELS.}

SPASMODIC COLIC, FRET OR GRIPES.

This is a very common complaint and has probably destroyed more horses than all other diseases: together, and still it is a disease that is most easily managed. I never knew a case where a horse died with colic when the person that doctored him knew what ailed him, and doctored him for colic. But men are so apt to go to doctoring for that imaginary disease bots, or to mistake the disease in some way, that it has resulted in the death of thousands of valuable horses.

Spasmodic colic is caused by a change of food, over driving, large draughts of cold water, standing in a draught of cold air, and in some horses. the digestive organs are so impaired that they are very subject to it. The pain is caused by a griping or pinching together of the outer coating of the intestines. Some call it cramp colic, and it is in reality cramping of this coating of the intestines. which pinches the intestines together and causes. that extreme pain; then it will relax, let go and 


\section{3}

the horse will be partially easy for a short time, when, perhaps, the spasmodic action will seize some other part of the gut, and so continue on, dodging about from place to place. After death the places where these spasms had seized the gut, may be easily recognized by the light or pale appearance, and being darker each side. Some owners of horses suppose that they never have the colic unless they bloat or swell. We often see men having colic and no bloating, and why not a horse? In fact there is probably twenty cases of colic where the horse does not swell to one where he does.

The symptoms are perhaps a sudden catching up of the hind leg, or pawing with the forward foot, switching the tail, looking around toward the side, biting at the side, turning up the upper lip, hump up and lie partly down, perhaps lie clear down, paw, kick and thrash about, perhaps lie down and roll over on the back, and show by all means that they are suffering pain in the bowels. If the horse is discovered when first attacked, perhaps a handful or two of salt thrown into the mouth and a little gentle exercise will relieve him, but if not better in ten minutes give the following: $1 \mathrm{oz}$. tincture of opium, $1 \mathrm{oz}$. sulphuric ether, $1 \mathrm{oz}$. tincture of camphor, half a pint of water. If not better in thirty minutes repeat, and in bad cases this may be increased, even 
doubled with safety, and continue to repeat every thirty minutes until relieved. I never failed in curing a case of colic with the above, alone, where there was enough life left in the patient for the medicine to have time to take effect. I have given this recipe to some men living who would not do without it for hundreds of dollars. Every owner of horses should prepare some of this, cork it up tight and keep it on hand, as colic is so common and the cure so sure and easy.

\section{WINDY COLIC.}

This is caused by a sourness, or fermentation of the food in the stomach, which generates gas that bloats or swells the horse and causes intolerable pain. Death is caused by the gas rupturing the stomach or some of the intestines and escaping into the cavity of the body and pressing against the midrif, or diaphragm, with such force that the lungs can not be expanded, and consequently ends in suffocation; or the stomach may be distended by the gas without rupture so as to produce suffocation or smothering. This disease is usually very rapid in its course, and there is no time to be lost in applying remedies, after you are sure what ails them. The symptoms are about the same that they are in spasmodic colic, with the addition of the bloating. Give the following: Tincture of opium $1 \frac{1}{2}$ oz., saleratus $1 \frac{1}{2}$ oz., tinct. of 
camphor $1 \frac{1}{2}$ oz., sulphuric ether $1 \frac{1}{2}$ oz. Mix all together, add one pint water. Repeat every half hour until better, and in the mean time it is well to give one or two injections of soapy water, adding a hand full of salt or a little red pepper tea, or something to stimulate the rectum, so as to aid the escape of gas. In bad cases it is best to introduce the hand into the rectum and remove the hard dung so as to open the passage.

\section{INFLAMLATION OF THE BOWELS.}

This is produced by many different causes, such as severe attacks of colic, acid in the stomach and bowels, foreign substances, cold and sour grass, over exertion, change of food, foul air, generating from filthy stables, \&c. The attack may be apparently sudden, or it may be slow in its approach; or it may commence by scouring; or there may be constipation of the bowels. The disease is usually ushered in by repeated shivering fits, and then attacks of colic; and if not careful, it will be mistaken for colic, for they will go through the same motions that they do with colic, but the pain is usually more steady than it is with colic. The horse is very much tucked up in the flank, breathes short and quick. By pressing against the bowels with the hand, he will flinch, showing soreness; the pulse will be quick, small and wiry, the color of the nostrils 
will be almost a scarlet red, the tongue scarlet red, the edges a purpleish color in the center; but the symptoms are always so obscure and mixed, the derangement being so general, that it is oft times difficult to determine; but there is one test that will make it perfectly plain. Introduce the hand into the rectum and remove the hard dung, which will usually be covered with streaks of slime. Then again introduce the hand as far as possible, and let it rest for a moment, and you can readily tell whether it is the heat of inflammation or the natural warmth of the body.

Treatment.-Take $\frac{1}{2}$ oz. of calomel, and mix enough of flour with it to make into four pills ; give one every two hours, and in two hours a fter giving the last one, give one pint of linseed oil and repeat the oil every eight or ten hours, until it operates, and in the mean time, give the following : $\frac{1}{2}$ oz. tincture opium, $\frac{1}{2} \mathrm{oz}$. tincture of camphor, $\frac{1}{2}$ oz. tincture of rhubarb, $\frac{1}{2}$ pint water. Give every half hour until the pain is relieved, then, afterwards, whenever the horse is in pain, until the physic operates. If the physic operates too much, add $\frac{\pi}{2} \mathrm{oz}$ tincture of capsizum, and continue to give every half hour until checked. This disease is sometimes very rapid in its effect, producing death in eight hours, and at other times lingering for weeks, and finally assiming a chronic form. You should be very care- 
ful about the food. Green grass is best if it can be obtained; if not, scalded oats, porridge or gruel, but do not give them any bran mash, as it acts in this case almost like poison. If the disease as. sumes a chronic form, or the horse does not do well afterwards, give the cleansing powders for a weck or two, so as to regulate the whole system.

\section{ACUTE DYSINTERY.}

This is caused by some accursed substance being taken into the stomach, either as medicine or by accident, and is usually first discovered by fre. quent watery discharges from the bowels, attended by some pain and griping, and after a time by great thirst. Give the following: $1 \mathrm{oz}$. tincture of opium, $\mathrm{I}$ oz. tincture of camphor, $1 \mathrm{oz}$. tincture of rhubarb, $\frac{1}{2} \mathrm{oz}$. saleratus, 1 pint of water, and give one-half the above dose every half hour until the discharge is checked. Let the horse drink freely of linseed tea or slippery elm tea, or a weak solution of gumarabic. Be very careful about the food. Allow them only cooked food, and the above teas for a week and gradually bring them back to dry food by giving small quantities at a time.

\section{CHRON1C DYSINTERY}

Is most frequent with very old animals that are poorly kept. It commences by a looseness of the 
bowels, which should be early attended to. The food should be immediately changed, and only the most nourishing and sound kind allowed, and give the cleansing powders. But if the disease continues, give the following: $1 \frac{x}{2}$ oz. tincture of opium, $\frac{1}{2}$ oz. tincture capsicum, $\frac{1}{2}$ oz. tincture camphor, $\frac{7}{2}$ oz. tincture rhubarb every hour or two, as the case may require, continuing the cleansing process for two or three weeks.

\section{WORMS.}

Horses are subject to all the different kinds of worms that people are, and they frequently produce serious difficulty. The symptoms are a slight cough, and dullness, a deranged appetite, wasting of flesh; dry harsh feeling to the skin and hair, staring coat and especially across the loins each hair stands erect as though afraid of its neighbor; occasional patches of slime covering the dung, the anus being partially covered with a yellowish substance or stripes of yellow slime hanging down. I think that the best medicine that I have ever seen for worms is the cleansing powders, to be giv en for a couple of weeks, adding $\frac{1}{2}$ oz. calomel. This will clear the stomach and intestines of worms and regulate the whole system.

\section{INFLUENZA}

Is supposed by some to be contagious, but I think it is more frequently brought on by impure 
air, improper food, \&c., than any thing else. It is marked by a general derangement of the whole system; stupor or weakness, swelling of the legs and joints, swelling of the head and lips; will perhaps be very lame in one limb, the limbs being hot and tender; short breath, copious tears, sore throat, tucked up flanks, compressed tail, hot feet and in fact, the horse seems to be affected in every part; consequently we want to rouse up the whole system by acting on all the organs at once. First, wash the whole body over with saleratus water, wiping it dry, then give the following: $\frac{1}{2}$ oz. calomel, $\frac{1}{4}$ oz. gum camphor, $\frac{1}{2}$ oz. aloes, $\frac{1}{2}$ oz pulverized saltpeter, 2 oz. ginger. Mix all together, add enough flour to make it into pills, divide into four pills, give one every four hours. Then in four hours after giving the last, if it has not operated give 1 pint of linseed oil, and wash the legs frequently with a half oz. of blue vitriol dissolved in two gallons of water, and it is well to steam or smoke the horses head every few hours until there is a copious discharge from the nostrils being careful that he does not take cold afterwards. The steaming or smoking is done by throwing a blanket over the horses head and holding a kettle of hot water or boiled herbs under the nose; or to smoke, build a fire in a kettle or on a shovel, and put tar or old leather on it so as to create a stinking smoke and hold it under the nose and continue 


\section{0}

this until the breathing is easy. Do not give any active physic, or bleed, blister or rowel for all such treatment has too great a tendency to wealen the system which is already exhausted. But we should rather try to strengthen and only give enough medicine to cause each organ to perform its proper office until the disease is thrown off. 


\section{CHA.PTER IX.}

\section{DISEASE OF URINARY ORGANS.}

\section{INFLAMMATION OF THE KIDNEYS,}

Happily is not of so frequent occurance as it formerly was, since most horse owners have abandoned that very injurious practice of frequently giving horses niter or rosin, or something to keep his water right; there is no more necessity for giving a horse medicine to regulate his water than there is a man. But inflammation of the kidneys may be caused by musty hay or bad oats, or bad and foul air. The symptoms are a straddling gait, humped up back, flinching when there is pressure made on the back, frequent turning of the head around toward the hind parts, a hard and quick pulse, short and quick breathing, and scanty urine, and will almost refuse to turn short around in the stable.

The treatment is, first, apply a strong mustard poultice across the back, and give the following drench: $\frac{1}{2}$ oz. tincture of opium, 1 oz. spirits of nitre, $\frac{1}{2}$ oz. tinct. of camphor, 1 oz. tinct. lobe- 
lia. Mix and add $\frac{1}{2}$ pint of water, and give every two hours until relieved; keeping on the poultice, and be careful to keep it moist.

\section{INFLAMMATION OF THE BLADDER}

Is not a very frequent disease, and the symptoms are similar to inflammation of the kidneys, only instead of the roached back, the back will be rather dropped down more than usual, the water is discharged in small quantities and frequent. The treatment is the same as inflammation of the kidneys, only omit the poultice.

STOPPAGE OF THE WATER OR SPASAI OF THE URETHRA.

This disease has been frequently mistaken for colic or inflammation of the kidneys. It is not near so frequent a difficulty as is supposed by most horse owners. Mares are very seldom troubled with it. It is easy to detect from the wide spread legs, or straddling movement of the horse, the pain being constant, the absence of any discharge of water, but the frequent effort, attended with pain, shown by a gruntirg noise; and if there is any doubt about it before giving medicine introduce the hand and arm into the rectum, and feel below the bumb gut, and you can readily feel the bladder, and see if it is so full as to cause pain. Now instead of giving the 


\section{3}

usual remedies, such as nitre, rosin, \&c., which only increase the quantity of water, and add to the difficulty, our object should be to relax the system so as to cause the spasm to pass off. Take $2 \mathrm{oz}$. of tincture of opium, and $2 \mathrm{oz}$. of tincture of lobelia, mix together, add $\frac{1}{2}$ a pint water and give the whole at one dose, and if Lot better in twenty minutes or half an hour repeat the dose, and inject with a syringe, through the penis, some of the same preparation, and continue as above, even though you give repeated doses, until the water passes freely.

\section{STONE OR CALCLLUS IN THE BLADDER.}

'The only way to detect a stone in the bladder, to any certainty, is to examine by introducing the hand into the rectum and examine the bladder and if there is a stone it may readily be felt with the hand. But this is of but little benefit to the horse owner, as there is no medicine that can reach it, and the only cure is by a surgical operation, which is very dangerous, even when practiced by a skillful Veterinary Surgeon. A horse that is troubled with these calculus growth is subject to severe troubles in passing the urine, which will get worse as time goes on until eventually it will cause death. 


\section{4}

\section{BLOODY URINE}

Is a discharge of blood with the urine, sometimes in clots, and at others merely coloring the water. When there is a copious discharge of blood there will be no pulse at the jaw, the pupils of the eye will be dilated, the breathing short and quick, the head down, the back roached up, the membranes of the nose are colorless and cold, the flanks tucked up, the legs widely straddled; to raise the head and hold it up for a minute would cause the horse to stagger.

The treatment consists in disturbing the horse as little as possible. Give the following: two drams of sugar of lead, dissolve in half a pint of water; if not better in twenty minutes repeat the above, adding $1 \mathrm{oz}$. tincture of opium; if this does not do, dash two or three buckets of cold water on his back, standing up over him so as to let it fall some distance, and inject some of the cold water into the rectum, as the cold may stop it; or, as a last resort try this; ergot of rye 4 drams, pour half a pint boiling hot water on to it, and when cold add one oz. tincture of opium, and give at one dose, and continue the pouring of the water on the loins; and if this fails wait six or eight hours and repeat as before. 


\section{5}

DIABETIS, OR TOO FREE A DISCHARGE OF URINE.

This is caused by medicines that have been given, or improper food. Give one dram iodide of potasium, dissolved in half a pint of water, twice a day until relieved. 


\section{CHAPTER $X$. \\ DISEASES OF THE SIIN.}

\section{MANGE.}

This is horse itch, and corresponds to the itch of the human subjects, and originates from the same cause, and usually first appears on the skin under the mane. By examination you will find a quantity of dry scurf, and the horse will scratch or rub against any object that may be within reach. This loose scurf will spread over the neck and shoulders, and if allowed to run on will extend over the whole body, but scarcely ever effect the legs. Rub the part affected with sulphur oint. ment every day, and give the cleansing powder's for a week or two.

\section{RING WORM}

Is a small round spot where the hair falls off, leaves a bare spot, and increases in size. Take 1 oz. oil of tar and mix with $1 \mathrm{oz}$. of lard, and grease the part every day, washing it with soap and water before applying the ointment.

\section{SURFEIT}

Is small blotches or spots, ressmbling heat blotches 


\section{7}

that raise on the skin of the human subject in hot weather. They raise up in round, blunt lumps. Give the cleansing powders until some time after the disease entirely disappears, so as to get it all out of the system.

\section{HIDE-BOUND}

Is not a disease of itself, but the result of exposure, bad or insufficient quantity of food, or the result of some other disease. The food should be of the best quality and plenty of it. Give a handful of salt every day in the food, and give the cleansing powders until the constitution is improved.

\section{LICE.}

Horses oftentimes get lice by allowing chickens to be in the stable, or by having to roost too near the stable; but most generally they are generated by a diseased condition of the animal. To remove the lice merely grease the whole body over with any kind of cheap grease, and then attend to whatever disease there may be. If there does not seem to be any particular disease, then it is a derangement of the whole system, and I give the cleansing powders in such cases for two or three weeks, so as to improve the genural condition.

\section{LARVE, OR GRUBS IN THE SKIN.}

These are caused by the deposit of an egg from the fly on the horse's back, and the warmth of the 
horse hatches the egg into a sort of maggot which burroughs into the skin and remains until the next spring, causing a small lump to rise which is quite painful to the horse, and very annoying to the owner. The best and surest way to get them out is to open a small hole through the skin and squeeze them out, and then apply any healing application to the wound that may be at hand.

\section{WARTS.}

Warts are of two kinds, one being lumps forming under the skin and having a smooth surface, and seeming loose when felt of with the hands. These should be opened with a knife, when you will find a sack formed there. The contents should be removed and then treat it as any other fresh wound. The other kind forms on the outside of the skin, usually having a snall base and rough surface, and generally increases in size, and are oft times bloody, and it is supposed by some that the first wart breeds others; others claiming that the appearance of numerous warts on the skin only shows a tendency of the system to promote such growths. Certain it is that where there is one wart others are very apt to appear, consequently there should be no time lost in destroying them. I think the best way is to cut them off with a knife and then to sear or burn the part, with a hot iron, to stop the bleeding; or, instead 
of burning, you might apply a solution of lunar caustic, say ten grains to half an ounce of water, or any other plan to stop the bleeding. Some take them off by tying a small cord around them and allowing them to slough off, and others remove them by applying lunar caustic every day, say ten grains to half an ounce of water, merely wetting the wart with the solution. This will take some time, but will accomplish it in the end; or almost any kind of caustic medicine, if applied long enough, will remove warts.

\section{TUMORS}

Are of so many different kinds and forms, and come in so many different locations, that it is im. possible to give a complete description of all. Some of them may be safely removed with the knife, while others should be let alone, as there would be great danger in removing them. The better way is when a horse has any enlargements. or unnatural growths, before being operated upon, some experienced person should be consulted as to the safety of making the operation. There is a peculiar kind of enlargement which comes upon grey horses, called mellaniosis, which will be spoken of in its proper place, and which the young practitioner had better notice before operating on a grey horse for any kind of tumors. The only way to remove tumors is by cutting out. (See Operations.) 


\section{SWELLED OR STOCKED LEGS.}

This is a very fiequent complaint, especially in the fall of the year when horses are taken from grass, and is caused by a want of circulation in the limb. Usually a good rubbing with the hands and exercise every day will relieve the difficulty, but should it remain and continue to get worse, while the horse is apparently enjoying good health, then we must resort to an operation to get up a renewed action in the limb. Make a hole through the skin, the size of a pen knife blade, on the outside of the leg, about four or five inches back of the stifle joint; then insert, under the skin, in a downward direction, a quill or tube and apply the mouth to the tube and blow wind under the skin, and push it down the leg by applying the hands on the outside and rubbing down until you have got enough wind introduced to cover the whole limb from the stifle joint to the hoof, leaving the wind there. It will escape through the pores of the skin in a few days. Then apply the following: 2 oz. turpentine, 1 dram of carbonate of amonia, dram venitian red; mix to. gether and apply with a small brush, all over the leg, enough to merely moisten the hair, being careful not to get too much in one place, as it might blister. One application is enough. Then give the horse exercise, say to go five or six miles every day for two weeks. The limb will be some 
swollen and considerably stiff and sore for a few days after the operation, but pay no attention to that but attend to the exercise and it will come all right. But you should bear in mind that if a horse that is troubled with legs that will stock when standing without exercise, is out of condition in any other way, or other diseases are troubling him, he must have those troubles attended to before making the above operation.

\section{SITFAST.}

Sitfast is a sore usually located on the back of the horse, and is generally caused by a bad saddle. It is a sore with a black spot in the centre, the spot being composed of a hard substance resembling a piece of horn, which holds very tight to the flesh. Cut out the hard or black spot and then treat as any other sore. There is a very good application, which you will find in the back part of this book, called Healing Wash for Old Sores.

\section{GREASE HEEL}

Usually shows itself in the form of scratches, and is caused by filthy stables, running out on cold and wet ground, or by cutting the hair from the leg and exposing it to the cold and wet. But it does not always commence as scratches. It may be occasioned by the leg getting poisoned 
with poisoned weeds, or being injured with a rope getting round the leg below the fetlock, and in fact, most any injury to the leg below the fetlock is liable to result in grease heel. When it is grease heel, the leg will be very hot and tender. There will ooze out of the leg a fluid that has a very miserable, bad smell, and if this is allowed to continue, after a while there will little bunches raise up below the fetlock, resembling a bunch of grapes. This becomes a blood disease. That is, the whole system becomes affected. Wash the leg every day with castile soap and soft water and rub it dry. The horse should have one hour's walking exercise every day. Give the cleansing powders twice a day for two weeks if the leg still continues sore. Use the healing wash for old sores on the leg twice per day until healed and all the inflammation is gone, being careful to wash as before every day, and to continue the cleansing powders for a couple of weelss after the disease has entirely disappeared, so as to be sire not to have it return again.

\section{MALANDERS AND SALLENDERS}

Are small patches of rough scurvy skin located on the leg. Malanders appear on the back of the knee. Sallenders appear on the front part of the hock joint, and if allowed to remain, are liable to kecome bad sores. Wash the part with castile 
soap and rub every day, and apply the healing wash for old sores twice a day.

\section{SCRATCHES UR CRACKED HEELS.}

This is caused by neglecting to keep the legs clean, or by exposure in cold or wet weather, or by running on low, wet ground; and if not cured, are very liable to terminate in grease heel. Wash the leg every day with castile soap and water, and rub until it is dry, and if the horse is allowed to go out, it should be washed every time he comes in, so as to be sure to keep it clean. Then every time after washing, apply the following: Take a table spoonful of fine gun powder and mix enough lard with it to make a salve, and rub it in with the hand. 


\section{CHAPTER XI.}

\section{SPECIFIC DISEASES.}

\section{HEAVES OR WIND.BROKEN.}

Most authors on horse diseases call heaves wind-broken, but as it is understond in this country, they are two separate diseases. Heaves are brought on by anything that will create irritation of the lungs; being much in the dust, taking cold, musty hay, eating large quartities of food and being fast driven immediately afterward, are among the causes that produce irritation of the lungs, which causes the mucus membrane that lines the air cells of the lungs to become thickened, which partiy closes the air cells, and causes the labored effort in breathing, and is known by hard breathing, that is much worse by being exercised, and a peculiar jerking motion of the flank. This disease there is no cure for, because we cannot reach the lungs directly with any medicine that would reduce the thickening of the membrane. All that we can do is to relieve as much as possible. A horse with heaves should be allowed but a small quantity of hay at a time, and be kept 
entirely away from any dust, and give a teaspoonful of tartar emetic once per day as often as is necessary to give relief. Give it in the feed.

\section{WIND-BROKEN}

Is the ruptured air cells of the lungs, caused by violent exercising. When the horse is standing he does not show any difficulty of breathing, but on moving, he breathes hard, with a peculiar roaring sound, and on stopping, the breathing becomes regular almost instantly. For this distressing difficulty there is no remedy, although there are some unprincipled horse dealers that fix such a horse so that for the time being he shows no difficulty, so as to defraud some unsuspecting person. This is done by making a hole into the body with a small knife, immediately above the anus and below the tail. Solong as this hole remains open, the breathing is regular, but as soon as it closes, the difficulty appears again.

\section{MELLANOSIS}

Is a disease that is scarcely ever found on any but gray horses. It usually commences on the tail, though it is many times found on other parts of the body. It is a small black lump with a smooth surface, and should it be cut into there would be found a black, inky substance. The lumps remain for years without any 
apparent injury, then, all of a sudden, increase to an enormous size. There are sometimes a number of them. I have seen cases where the whole tail was covered with these unsightly black lumps, besides those appearing on other parts of the body. On dissecting a subject of this kind, it is astonishing what a number of these came lumps we find, affecting the internal organs, and in fact, the whole system will seem to be affected by them. When the lumps appear on the skin do not attempt to do anything for them, as by doing so, you would undoubtedly provoke the growth and make it much worse than before. The only way is to let them alone, and if they get to such a size as to destroy the usefulness of the animal, put him out of his misery.

\section{WATER FARCY}

Is caused by anything that has a tendency to reduce the system; over work, insufficiency of food, bad food, filthy stables, foul air, want of exercise, are all causes of farcy. This disease in this country usually shows itself by a swelling under the belly around the sheath, along on the belly, and may continue into the breast, or it may attack one of the limbs; it scarce ever attacks two limbs at the same time. When it comes on the belly it usually is slow in its progress, and is not very painful to the horse; by pressing the fingers against the 
swelled part it will leave a dent that will remain for several minutes; when it attacks one of the legs it is usually sudden, you might leave the horse apparently well, and in one hour return and find the animal holding up one limb, and one of the joints swollen badly, and the horse suffering great pain; the limb seems very tender to the touch. In a case of this kind I commence by putting rowels in the breast, and if the case is a bad one into the swollen parts also; I then wash the swollen part every day with castile soap and soft water, and hand rub it until it is dry; I then give the following: 4 oz. pulverized blood root, $4 \mathrm{oz}$. pulverized gentian, 4 oz. pulverized golden seal, $\frac{1}{2}$ oz. crude antimony, 2 oz. pulverized nitre and $\frac{3}{4} \mathrm{oz}$. of calomel. Mix altogether and give a large tablespoonfull twice per day in the food, and if the horse will not eat it mix it into pills by adding a little flour and molasses, and put it down them; keep the bowels loose by giving bran mashes, or if necessary some mild physic, just enough to loosen the bowels. Water Farcy is a species of dropsy, so do not bleed or give any powerful physic, as he needs strengthening instead of weakening.

\section{PURPURA HEMORSHAGICA,}

Or commonly called swelled head. The cause of this disorder is not well understood, for it is not many years since it first made its appearance, 


\section{8}

but it has now become quite common, and it usually is sudden in its attack and may cause death in a few hours, or it may linger on for several days, and many times get well, but as a general thing the treatment is not very satisfactory. The horse might be left at night apparently well, and on opening the stable in the morning be found with the head, nostrils and lips swelled enormously, besides being swollen in other parts of the body, and the swelling will increase until there will ooze out of the skin a fluid often times mixed with blood, and there will be great difficulty of breathing, and the tongue will often times swell so that it will protrude from the mouth. If the tongue swells so as to protrude there is great danger of its being bitten off, so there should be no time lost in returning it to the mouth. First make two or three small cuts in it, say three eighths of and inch deep, so as to let it bleed a little, then rub and work it with the hand until the swelling is enough reduced to return it to the mouth, then give the following: 1 pint of linseed oil, $1 \mathrm{oz}$. tinct. of camphor, $1 \mathrm{oz}$. of spirits of nitre, $1 \mathrm{oz}$. suJphuric ether, and 1 oz. tinct. of lobelia. Mix all together and give in a drench, and if not breathing better in half an hour, repeat the dose, and if not better in one hour give $1 \mathrm{oz}$. of sulphuric ether, 1 oz. tinct. of camphor, $\frac{1}{2}$ oz. tinct. of lobelia, and $1 \mathrm{oz}$. spirits of nitre, in 1 pint of 
water, and repeat every hour until easier. Wash the whole body and limbs over in saleratus water, and rub dry every day, and give the swelled parts a plenty of hand rubbing.

\section{DISTEMPER OR STRANGLES.}

This is a common complaint among young horses and sometimes attacks old ones, and is supposed to be contazious. They usually have the disease but once. It is a swelling of the glands, under the jaw, and attended with some fever and soreness of the throat, and is supposed to produce the same effect on a horse the measles does on the human species, and so wants treating on the same principle with measles. The object is to keep it on the outer surface; and so with disiemper. The object is to get it to discharging out of the system as soon as possible. Many horse owners are in the habit of bleeding and physicing; I think this has a tendency to drive it back into the system and to cause other diseases. When a horse swells in the glands under the jaw with distemper, put a poultice on it of common brown sugar and bar soap, equal parts, being careful to keep it moist, and so that it will fit so tight that the air cannot get under it, and keep it on until there is a soft place on the swelled parts that shows that matter has accumulated there, and the sooner you get it to discharging out of the system the better. So 
open it with a knife, inserting the knife about $\frac{3}{4}$ of an inch; be careful to make the hole large enough so that there may be a free discharge. It is necesary to keep a good warm bandage on after taking off the poultice to prevent taking cold; sometimes by bad management, taking cold or other causes, the matter may not all be discharged, and is carried back into the system, and they break out in ulcers, or the legs swell. If there are ulcers treat them with the poultice, and open as soon as soft; if the legs swell wash the whole body with salaratus water, and rub dry with cloths or a brush; put rowels into the breast and give the cleansing powders twice per day, so as to get it out of the system; the cleansing powders should be given for a week or ten days after the swelling has disappeared.

\section{GLANDERS.}

This is a loathsome disease, and one that is highly contagious. It will in some cases produce death in one week, while in others it assumes a more chronic form and will linger on for years. It is a disease affecting the whole glandular system, not as some suppose, confined to the glands of the head and throat, but the whole system is affected, and particularly the lungs. In chronic cases the lungs are effected almost like consumption of the human subject. The first that is us- 
ually noticed is a discharge from the nostrils of a thin fluid that may only discharge at times. In this stage there is no certain test for it, but in a short time the discharge will assume a more yellow cast and will stick to the edges of the nostrils; by looking into the nostril there will be ulcerated places found, perhaps high up, so that it will require care in making the examination. By taking a little of the matter that discharges from the nostril and feeling of it between the finger and thumb, it will have a sticky feeling. There is no cure for this terrible disease, and the best way is when a horse is suspected of having the glanders put them by themseles where there is no danger of others taking it, until it is confirmed, and as soon as certain, destroy the horse, and cleanse the premises in every part where the horse has been. It is necessary for persons that go about glandered horses to te careful and not get any of the matter onto the skin where there is any fracture, or into the nose or mouth, or any of the light membranes, as by doing so they would take the glanders, which would certainly result in death.

\section{BUTTON FARCY}

Is of two kinds, the big and the little. The large usually makes its appearance on the inside of the hind legs up towards the body, while the small 
may come in any part. It is caused by being kept in filthy places, neglect in grooming, want of exercise, bad food, or it may be taken by innoculation. It seems to be of the same nature as glanders. A horse may be innoculated with gleandery matter and have the farcy, or they may be innoculated with farcy matter and have the glanders. When they are attacked with farcy they have the glanders before death, and when they are attacked with glanders they show symptoms of farcy bef re death. Farcy is a lump rising up under the skin, and there are many times numbers of them, and sometimes only one that ulcerates and discharges a yellowish fluid, and becomes a running sore. I have cured many cases of farcy, and some very bad ones, by giving them the cleansing powders alone. To give them twice a day for some time after there is no appearance of the disease, but it is well to grease the sores with sulphur ointment, and also put rowels into the breast.

\section{YELLOW WATER.}

Yellow Water is what in human subjects is called jaundice. Many men have the notion that whenever the hairs in the mane and tail become lnose so that they may be easily pulled out, and especially when the ends look yellow, that it is a sure symptom of yellow water. At any time 
when the horse becomes very debilitated or run down the hairs in the tail and mane are apt to become loose, so that it cannot be taken as a symptom of yellow water; it is only a symptom of debility. This disease is readily detected by the white of the eye assuming a yellowish color, and the edges of the eyelid, the nostrils and the roof of the mouth will all assume the same color. It is rery common for horse owners to exsuse their own negligence and penuriousness by claiming that the horse has got the yellow water. They neglect to give the horse proper grooming, and leep in a filthy and unhealthy stable, and either a miserable quality or scant supply of food, and many times over-worked; and then, when the horse fails in flesh, becomes stupid and dull, and has become too weak under his accumulated bad treatment to do his daily task, then they excuse their own faults by saying the horse has got the yellow water, or has become hide bound, when a little more attention and good food would remedy the whole difficulty. Yellow water is a bilious difficulty, and consequently is more frequent in warm than in cold weather. It is a diseased liver, and the way to treat it is to give the cleansing powders, adding $\frac{1}{2} \mathrm{oz}$. of calomel. 


\section{CHAPTER XII.}

\section{DISEASE OF THE LIMBS.}

\section{BONE SPAVIN}

Is the result of some injury to the joint. Some suppose it to be hereditary, but this is doubtful, any farther than like begets like. So a horse or a mare that has naturally weak joints, the offspring would likely be the same, and of course, according to the strength of the joint is the liability to complaints of this kind, and I might here say that it is poor policy to breed from stock of this kind, as it only brings into the world an animal that is of but little use or benefit to the owner. Spavin is first an injury to the joint, that produces inflammation of the sinovial membrane that surrounds the joint, and the cartilege that covers the ends of the bones becomes diseased, the sinovial fluid which lubricates the joint is dried up or absorbed, there is a bony deposit formed there that is of a porous nature; it is attached to the bone and there is no removing it with medicine, and even could it be removed, I think it would be bad practice, for it seems that 
nature has deposited this bony matter there to strengthen the already weakened joint. The way to manage diseases of this kind is to take them on the start and remove the disease before there is any enlargement. Spavins are of the bony character; are usually located on the inner and lower edge of the hock or spavin joint, or what some horse owners call the knee of the hind leg. They are sometimes found higher up near to what is usually called the gambrel joint, and in fact any bony enlargement there is about this joint is called spavins, as they are all caused in the same way, but the difference in location oft-times make a difference in the lameness. To examine for spavin always go in front of the horse and stoop down so as to look through between the forward legs at the hind legs, having the horse stand the hind legs as near alike as possible, then you can compare the two together, and in this position you can detect a spavin when it is not preceivable in any other; if you do not see any enlargement then place your hand on the joint, let it rest a moment and see if you cannot detect a little heat more than there should be; if not yet satisfied, have the horse led along on the level ground and notice his step; compare the step of the hind foot with the track of the forward foot, and if you find that with the lame leg he does not step as far ahead as he does with the well one, then 
mark it down as a certainty that the lameness is in the spavin joint, and spavin will undoubtedly be the result if not cured. Horses may be lame for months and even years in the primary stage of spavin before there is any enlargement, while with others there will be an enlargement within a few weeks after lameness shows. There are many cases of spavin, where there are so many different organs surrounding and composing the joint that are effected that there is but little can be done for them. There are also roany of them that have been of long standing and been doctored with all kinds of quack medicines, until the parts seem to have lost their vitality, and medicine produces no effect. There has undoubtedly been more cruelty, quackery and ignorance displayed on this disease than any other disease that horse is heir to. Whenever you meet with a pretender that claims to take off spavins or ringbones, and thereby make the animal more valuable, set him down as either being ignorant or a swindler, and have nothing to do with him. Do not allow a faithful servant to be tormented by such pretenders. I have tried many different remedies and have seen the result of many others, and I am satisfied that the prescription which you will find in the back part of this book is the best ever known. 


\section{SPLINT}

Is a small bony enlargement usually located on the inside of the forward leg, below the knee and above the ankle joint. They scarcely ever cause lameness only when first coming. They usually disappear before the horse is nine years old. Sometimes they are located so near the knee joint that they interfere with the joint and cause lameness. Sometimes we find them located on the outside of the hind leg, below the hock, but they scarcely ever cause trouble. Splints can usually be removed in a few days by applying the spavin and ringbone medicine. (See back part of this book.)

\section{RINGBONE}

Is of the same nature as spavin, (see article on spavin,) and is produced by the same cause. It may be low down near to the foot or it may be most up to the ankle, all on one side, or all in front, or on both sides, on the forward or hind limb, and in fact, any hard, bohy enlargement, forming from any cause, or in any shape, between the ankle and foot, is ringbone, and it should be treated the same as spavin.

\section{CURB}

Is an enlargement on the back side of the hock or sparin joint. There seems to be some dispute 
about the cause and character of curb, but is evidently the result of some injury to that part of the leg, either a strain or a bruise. In its first stage, when it is hot and tender, there should be a bandage put around the leg and kept wet with cold water until every appearance of inflammation has departed, then apply the spavin and ringbone medicine. (See back part of this book.)

BOG SPAVIN, THOROUGHPIN AND WINDGALL.

Bog spavin is a soft enlargement on the front and inner side of the hock joint, and is caused by some injury that produces slight inflammation, and that increases the supply of the senovial fluid or joint oil, which lodges in a sack. Sometimes by pressing on the enlarged part with the hand, it would show through on the back side of the limb, or by pressing on the side, it will show through on the other side. It is then called thoroughpin.

Windgalls are soft enlargements in the vicinity of the ankle. Bog spavin, thoroughpin and windgalls are the same disease, and originate from the same cause, only being in different locations. They scarcely ever produce lameness, but are liable to undergo changes, and to be converted into bone, and to cause serious difficulties, though this is not common. The treatment is, in the first place, while the enlargement is quite soft, put a compressed 
bandage on. This is done by using a sponge that is of the proper size, or by using three or four thicknesses of cloth, and put a piece of cork over it and bind it on to the enlargement, so that it will make a tight and constant pressure on the enlargement; then steep some white oak bark in water until it is quite strong, then keep the bandage wet with this, and keep it on for ten days or two weeks. If this does not effect a cure, or the enlarged part appears to be somewhat hard, and feels more like gristle than it did in the start, then use the spavin and ringbone medicine. (See back part of book.)

\section{STRFNGHALT.}

This is a sudden jerking up of the hind leg. sometimes one and sometimes both being affected. With some cases it only shows itself when the horse first starts; with others, only when they are excited or going down hill, or standing over in the stable. With most cases it is worse in cold than warm weather, and is more frequent in high spirited horses. There seems to be a variety of opinions among our most scientific authors about the cause and location of stringhalt; some claiming that it is an affection of the muscles of the leg, others claiming that it is an affection of the spinal nerve, besides many other theories, all of which the author thinks are of but little account; but among 
all the different theories there are none of them that have found a cure. The author will not advance any theory as to the cause and location of the disease, but proceed to give the plan by which he has cured many cases, although he has tried it in cases where it produced no effect. First, fasten up the forward leg on the side of the horse you wish to operate on, and place a twitch on the nose, and let the attendant hold it while the operator makes a hole through the skin with a common knife, about three inches, directly back of the stifle joint, on the outside of the limb. Make the hole a little larger than a penknife blade, then introduce a tube or goose quill, something that you can blow through. Shove it down under the skin a convenient distance, then place the mouth on the tube and blow wind into it, and with the hands force it down the limb until it covers the whole limb clear down to the hoof; then take the following mixture : $\frac{1}{4} \mathrm{Oz}$. carbonet of ammonia, 1 tea spoonful of venetian red, $\frac{1}{2}$ pint turpentine, and with a brush merely moisten the hair all over, then with both hands, rub the leg up and down, using all your strength for about a minute to each leg, then give the horse exercise, say to go about six miles every day for two weeks. This has resulted in the cure of string halt in many cases under my direction, and I think will cure most if not all. 
SHOULDER JAM AND SWEENY.

What is usually understood by shoulder jam, stoved shoulders, sweeny, and old chronic cases of founder and chest founder, are ail the same thing, the same disease in perhaps a little different form. Neither one of the above terms conveys any idea what the trouble is, and still men are tenatious abont the name, and there is often times great dis. putes whether a horse is shoulder jammed or sweenied, when there is no difference in the disease. If I was to gire tha diffeulty a name I should call it chronic rhumatism, as it resembles that disease more than any other, but as there is but little difference I shall not stop to argue about the name, but to describe what the disease is and the cure, for I believe that most of the cases of horses that are stiff in the forward part may be cured. This difficulty consists in a stiffness or soreness of the forward part, sometimes only one limb or shoulder is affected, but more frequently both are affected, and shrinking or perishing of the muscles, perhaps the shoulder perish, or perhaps the shoulders, chest and arm of the leg, all shrink some. It is caused by some injury to the muscles, perhaps a founder, collar too large or too small, hard driving, a slip or strain, driving fast on hard roads, driving fast down hill, jumping fences, and in fact anything that injures the inuscles of the leg or shoulder enough to create an inflammation, 
will cause this diffeulty. The inflammation is usually of a chronic form, that is, it is not very severe, but there is inflammation there which you may readily convince yourself of by feeling of the skin on the shoulder of a stiffened horse, and a sound horse. With one you will notice a dry harsh feeling, and the other a soft and moist feeling, which shows that there is an inflammation that produces adhesion of the celuler tissue that is between the muscles and facia, or striffin that lays between the skin and muscle, then the muscles are as it were tied up, that is, the horse has not a free use of them, he can make a short step but he cannot reach out so as to travel off free. Well, now the cure would be to break this adhesion loose and then stimulate, and have the muscles used at the same time, and they will become restored. I know the plan which I shall recommend here has been tried in some parts of the country with poor success; but I believe where it has failed it was either when it was not properly applied, or else there was some other difficulty connected with it, for I certainly have cured hundreds of cases by this means. First examine the feet and see if they are contracted; (See article on contracted feet;) then see if there is no lameness of the coffin joint, (See coffin joint,) then examine the other joints, and if there are no enlargemeats then there is a fair prospest of a cure. Put 
a twitch on the nose and with a knife make a hole through the skin and striffin or facia that is immediately under the skin; make the incsssion on the lower part of the shoulder near down to the arm of the leg, and about midway of the shoulder, and introduce a pipe or tube, being careful to get it through the facia, then apply the mouth and blow wind into the tube and under the skin, and with the liands push up and down until you have introduced enough to cover the whole surface from the hoof to the top of the wethers, and with the hands push it clear down and up, and some of it around onto the chest so that it will cover it all over about alike, then with a common shaving brush apply the following : 1 dram of carbonate of amonia finely pulverized, one teaspoonful of vinetian red, and 3 oz. turpentine; shake well and apply just enough to moisten the hair, being careful not to get too much in one place or it will blister, for a few days after the horse will be very sore and stiff, but pay no attention to that, but make sure he travels at least five or six miles every day for the next two weeks; let the wind remain, it will work out through the pores of the skin in time. When you push the wind over be careful that it covers every part, and bear on to it with your hands with considerable force to be sure that it penetrates to every part, so as to break down all the adbesion. One operation and application 
of the medicine is all that is necessary in most cases, but in case the horse does not get entirely well, make another operation in a month or six weelzs. In cases of this kind if the feet are contracted doctor them at the same time.

\section{CAPPED KNEE.}

This is located in the forward leg, a soft enlargement and scarce ever produces lameness, it corresponds to the bog spavin on the hind leg, and is produced by the same cause, and is liable to the same changes, but it should in no wise be neglected as there is great danger of its causing open joint by weakening the sinovial membrane that surrounds the joint, causing it to become permanently stiffened or grown together. This should be treated the same as bog spavin, and in all these cases it is best to let the horse have rest while he is undergoing treatment.

\section{CAPPED HOCK.}

This is a thickening of the skin, and an enlargement under the skin on the point of the hock joint, on the back side, and is caused by a bruise. When this first appears it can usually be taken away by constant rubbing with the hand for a few days. Employ a man and let him do nothing but rub the enlargement with the hand; but if it has been on for a length of time and has be- 


\section{5}

come considerably hard, the only way is to cast the horse and lay the skin open, and with a knife take the enlargement out, and close the skin with a stitch or two. Do not cut out any of the loose skin but let it remain as it will eventually all shrink down and heal without a scar, but if you remove any of the skin it will leave a scar. This is a very safe operation, as there is no large blood vessels, and but little to contend with. The only difficulty there is about it is that it heals slow. The best healing wash to use after any surgical operation is chloride of zinc dissolved in water, say one grain to the oz. of water.

\section{CAPPED ELBOW.}

1

This is an enlargement on the joint, on the forward leg up next to the body, and is called the elbow joint. It is caused by a bruise, frequently done by resting that part on the shoe of the hind foot while lying down. I have often seen these enlargements opened, roweled and blistered, but never saw any benefit from it. The only way to get rid of them is to cut them out as directed for capped hock.

\section{THE STIFLE.}

It has usually been supposed by horse men that the stifle joint is very liable to get out of place, what is called being stifled; and I have seen 
much cruelty practiced on horses by causing them to stand on the lame leg by placing what they call a stifle shoe on the well leg. This is a very cruel and barbarous pratice, and should never be allowed, for such a thing as getting the stifle out is impossible, which any person can convince themselves of by merely dissecting the stifle joint of a horse or a beef. The stifle may sometimes get bruised or strained which may readily be known by the swelling and inflammation that will follow, and should be treated the same as any other strain, by making some cooling application. (See article on strains.) The stifle joint is made almost exactly like the knee joint of a man with the knee cap in front called the patella. This patella may sometimes get out of place, but it is not frequent. Some of our oldest practitioners that have practiced a life time, have never met with a case. It may readily be known by the limb being extended backwards, and impossible for the horse to bring it forward or to bear the least heft on the limb; the patella always slips on to the outside, so that it may readily be seen by there being a large lump on the outside of the joint. When this does occur, put a rope around the ankle of the limb and let two men take hold of it and stand in front of the horse and pull steadily while the operator stands by the side of the animal and prishes it into its place, and holds 


\section{7}

it there for a short time with the hands; then wash it frequently with oak bark wash make by boiling the bark in water and throwing a handful of salt into it; then let the horse rest for a few months; and if it is the first time, it may never trouble him again, but if the patelia lusated the second time, then it is liable to get out at any time, and the horse becomes worthless.

\section{BLOOD SPAVIN.}

This is a disease that is scare ever known now days. I have not seen a case in over ten years. It is an enlargement of the large vein that passes down the front side of the hook joint. A horse with blood spavin will actually suffer more pain than they do with bone spavin, and will be very lame. The only cure is to dissect the enlarged part, and tie a ligature above and below, and take the enlargement out entire. 


\section{CHAPTER XIII.}

\section{DISEASES AND ACCIDENTS OF THE FEET.}

\section{CRACKED HOOF.}

This may be on the front of the foot, called toe crack, or on the side, called quarter crack. It may extend from bottom to top, or it may only reach part way; in either case take a knife and cut the edges of the crack so as to form a groove, and let the inner edges come together; then put a stout shoe on the foot, and be careful that it is always kept tight so as not to allow the foot to spring; then either cut or burn across the top of the crack so as to start it to growing together. Then apply the following: linseed oil $\frac{1}{2}$ pint, turpentine $4 \mathrm{oz}$., oil of $\operatorname{tar} 6 \mathrm{oz}$, oil of arganum 3 oz., mix all together, and shake well every time before using, and apply every night after the horse is done work for the day, around the top of the hoof, about one inch down, enough to wet it thoroughly. This is to soften the foot and keep it growing. Continue this until the crack has grown out. 


\section{FALSE QUARTERS.}

False quarter is the absence of a portion of the outer or hard covering of the hoof, located on the side or quarter, and only leaves the soft, spongy under surface to protect the hoof. This of times will crack, when it does it should be treated as directed for cracked hoof. When there is found any granulated flesh gets into it apply the following: $1 \frac{1}{2}$ oz. blood root, $\frac{1}{2}$ oz. gum camphor, $3 \mathrm{oz}$. tincture of arnica, put all into 1 pint bottle, and fill it up with alcohol, and shake well; apply this three or four times a day until the proud flesh has disappeared and it has healed over, but it will be impossible to cause a new outer covering to grow. All that we expect to do is to make it as comfortable as possible.

SEEDY TOE.

This consists in a portion of the outer or hard covering of the hoof becoming loose, or there being a division between the soft and hard part of the hoof. The outer and loose part should be all cut away, and then apply the wash as for cracked hoof, and if possible let the horse rest for a time, until the foot becomes sound, and keep a stout shoe on the foot.

\section{CALKED TREAD, OR OVER-REACHING.}

This is caused by the horse stepping on to his own foot, cutting with the calks. Sometimes 
these wounds are slight; if but slight smear them over with tar to keep the dirt out, and they usually get well in a few days. But many times the wound will appear but slight on the surface and at the same time it is very deep. It is always best to examine it and see how deep it is ; if considerable depth, then there is great danger of its resulting in quitter. (See article on quitter.) It is necessary that the wound should be kept clean, not barely to wash the outside, but to use a syringe and cleanse it to the bottom; wash it out once per day with soap and water, then inject the cloride of zinc wash, say 1 grain to $3 \mathrm{oz}$. of water, and continue this until it heals. If proud flesh gets into it use the healing wash for old sores. (See back part of this book.)

\section{CORNS IN THE FEET}

Are caused by a bruise in the feet. They are usually caused by the shoe resting on the sole of the foot. In contracted feet, they are caused by the hard or horny part of the foot pressing against the laminary or soft part. They are seen when the blacksmith pairs the bottom of the foot. A red spot on the sole of the foot, near to the heel, between the frog and the rim. If it is a flat foot, cut the corn out as low as possible, put the shoe on, and in three weeks take it off, and cut the corn out again, as the corn grows faster than the 
rim of the foot, and the object is to keep it cut out often until the foot grows down and the corn has disappeared. If the foot is contracted, cut it out as before, and have the surface of the shoe that is next to the foot made in a convex form or slanted out, so that when the horse stands on it, the heft will cause the foot to keep sliding off on both sides and spread the foot without any injury, then apply the following: linseed oil, $4 \mathrm{oz}$,

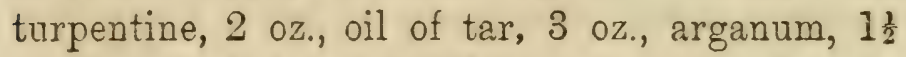
oz.; mix and shake well before using, and apply every other day around the top of the hoof, down one inch, enough to wet it thoroughly, and continue this until the corn has disappeared.

\section{QUITTER}

Is a running sore in the foot that discharges at the top. It may be caused by having the foot. cut by the calk of the other foot, or by a severe bruise immediately above the foot, or $b_{y}$ being pricked with a nail in shoeing, or getting graveled, and in fact, anything that injures the foot so as to cause matter to accumulate; and not having a free discharge, it burroughs deeper and deeper, forming pipes that branch off in different directions. The first appearance of quitter is a large swelling around the top of the foot, very hot and tender, and causing severe lameness. This should be poulticed until it becomes soft; 
then open it with a knife, making the cut as low down as possible; then inject into it twice or three times a day, the chloride of zinc wash, 1 grain to the ounce of water. If it has been of long standing, and there are pipes formed, which can be known by taking a splint from a broom and making the end smooth, and probe the sore, being careful to examine all around, and if there is a pipe formed, take some nitrate of silver, finely pulverized, and add three times as much flour, and mix well together; then wet the splint and dip it it into the powder and put it into the pipe, and repeat this untii sure that the powder has came in contact with every part of the pipe. This will cause it to swell and be very sore for about two days, then there will appear a sort of creamy discharge; then use the zinc wash to heal it, injecting in with a syringe.

\section{THRUSH OR CANKER OF THE FOOT.}

Thrush in the foot is a disease of the frog. It is caused by standing in filthy places, and may be known by a thin discharge from the frog, and portions of it sloughing off, and usually has a bad smell. Cut away all the unsound parts of the frog, then pore a little veniss turpentine on it, and warm it in with a hot iron, and keep the horse in a clean place. This scarcely ever causes lameness. Canker seems to be an aggravated case 
of thrush, and not only the frog becomes affected, but the edges of the sole are more or less affected, andinstead of portions of it sloughing off, there will grow rough, ugly looking lumps of fungoid, horny substance. All of the diseased parts should be out away, then apply the following: 2 oz. pulverized blood-root, $\frac{1}{2}$ oz. pulv. gum camphor, and moisten it with tincture of arnica; then put a shoe on the foot, and put the mixture on, and put some cloths over it, and fasten them there by springing some thin pieces of iron across, under the shoe so as to make it press well on the diseased part. Remove this in two days and cut away any diseased part that may appear, and dress again, and so repeat, until there is no more fungoid growths. Then take the same misture, and add enough tincture of arnica to make a wash, and apply two or three times per day until healed.

\section{FOUNDER.}

Founder may be produced by taking grain or water into the stomach when it is not in proper condition to receive it, or by an over-feed of grain, or over-driving, or taking a sudden cold that settles in the forward limbs, and may be known by the horse being very stiff, and getting the hind leg under the body so as to keep the weight off the forward limbs, which makes him appear as though he was stiff all over, when in reality, the 
difficulty is most all confined to the forward parts. It affects the muscles of the legs, and especially the inner or soft part of the feet. The horse will refuse to eat, the mouth will be very dry and usually very thirsty, and trembles as though having a chill. This may come on suddenly, or may be several days in coming on. It is what some authors call laminetus, which means fever in the soft parts of the foot. If this disease is not properly treated, the feet are liable to slough off, or the bone of the foot to be pressed down out of its natural place, so as to cause the foot to bulge on the bottom, and shrink away on the top side, and the toe of the hcof to become spongy, what is called pumiced feet, or it may affect the muscies of the leg in such a manner as to cause adhesion of the celular tissue, and result in permanent stiffness. When it is discovered that the horse is foundered, give a large dose of physie of any kind that may be most handy, then stand the horse in water that will come up to his knees. If this is not convenient, wind the legs with hay ropes clear up to the body; then take a tea kettle and pour cold water on them every few minutes until the physic operates, which will usually be in about twenty-four hours. If the physic does not operate within twenty four hours, repeat the dose, and be sure to keep the legs wet with cold water until the physic has operated; 
and in the mean time, give $1 \mathrm{oz}$. tincture of lobelia every hour, or as often as may be necessary to control the fever, which you can tell by the pulse. Do not bleed, for in doing so, you weaken the system, and make the more danger of the feet sloughing or breaking down. The reason why some bleed in cases of this kind is to lessen the fever. This may be done with the lobelia without bleeding. The object in this treatment is to keep the limbs cool, and ease the fever in the body until it can be physiced out, and to keep the fever down as much as possible in the mean time. I have practiced this treatment for many years, and have never failed of curing founder in its first stages, so that the animal was as sound afterwards as before.

\section{COFFIN JOINT LAMENESS.}

This is an injury of the gristly cartiligeous substance that covers the ends of the bones, done by fast driving on hard roads, or driving fast down hill, or jumping fences, or something of that sort; the cartilege is injured so that a low grade of im. flammation starts in, then ulceration takes place, and eventually the joint will become grown to gether. This is a disease that there can but little be done for, rest for several months is the best that can be done, but it is best for the horse owner to know how to detect this disease as it has always 
been considered very difficult to detect. By raising the limb backward and placing the end of the thumb into the hollow that is on the back side of the limb, down near to the foot, and press hard, and if it is the coffin joint lameness the horse will flinch badly; the horse will also travel mostly on his toe as though it hurt him to put the heel down. After the joint has become grown together it may be known by the stiffness of the joint, that it will not bend, and there will also be some enlargement on the back side in the hollow place just above the foot. A horse with this disease can be made most comfortable by keeping the toe of the foot pealed down on the bottom side, and not cut the heal, so as to keep the foot and ancle standing up as near like the sucking colt as possible. (See article on shoeing.)

\section{HOOF-BOUND AND CONTRACTED FEET}

Is caused by some inflammation in the feet, perhaps bad shoeing, perhaps coffin joint lameness or some difficulty of the limb or shoulder, so that the horse does not stand on it as much as on the others. In either case there is a fair prospect of a cure by having them shod properly. In order to cure, it is not best to keep the shoe on more than three weeks; it should have all the nails as near to the toe as possible, and from the back nail hole have the shoe made with a good deal of slant or 
bevel on the out side, so that the heft of the horse will cause the foot to slip off on to the out side and spread the foot by a gradual process; do not have the shoe spread with the tongs or any instrument as that is injurious to the foot; be careful to have the shoe the shape of the foot and no wider than the foot at the heel; then keep the foot soft by running in wet pasture, or by applying the following: linseed oil $4 \mathrm{oz}$. turpentine $2 \mathrm{oz}$. oil of tar 3 oz. arganum $1 \frac{1}{2} \mathrm{oz}$. Mix and shake, and apply every other day around the top of the foot one inch down enough to wet it thoroughly. By the end of three weeks the hoof will begin to spread over the shoe, then have it taken off and spread out with the fcot again, and so keep doing until the feet are out as wide as they should be. In determining whether a horse has contracted feet, lift up the foot and look on the bottom side; if it is contracted the space between the frog and bar of the foot will be pinched together. Sometimes only one side of the foot is contracted, then only have the side of the shoe beveled on that side, and treat as above.

\section{SHOEING.}

It is astonishing to see with what readiness men that have no knowledge of the antomy of a horse's foot, nor have spent any time in studying nature's designs, will give directions how a horse should 
be shod, as though they thought the foot of the horse was a block of wood that they could cut and carve to their own liking; they seem to think that the blacksmith has spent years of time only to learn to handle his tools according to their directions, and usually the more ignorant the owner of the horse about the true principal of shoeing, the more directions he will give to the smith, and especially if he thinks the foot is contracted, to direct it to be shod wide at the heel, which only makes the foot worse. Owners of horses are usually very much at fault in letting the shoes remain to long without being removed; no horse should be allowed to wear his shoes more than two months at one time, and a horse that is used on the road should be shod at least every six weelss because the toe of the foot grows much faster than the heel, and by leaving the shoe too long the toe gets grown out long, and throws the ancle back and strains the joint, and often is the cause of ringbone, windgalls, contracted tendons, thickened ancles, \&c.; and many times shoulder difficulties are caused by the toe being so long as to cause the horse to make false steps and strain himself in various places. A horse's foot should be kept as near in the same position as a sucking colt's as possible. I shall now proceed to give some plain instructions about shoeing, without argument, merely saying that I have practiced these principles 


\section{9}

for many years, and whenever these principles have been carried out as directed have never had any difficulty with the feet, and not only that, it will keep the feet in a handsome and neat form. When a horse is to be shod, the less noise and confusion the better he will behave, the blacksmith should never halloo at or scold a horse, and much less beat or strike them; if coaxing does not do, take some plan to confine them, as that is much safer and does not spoil the disposition of a horse or smith. When the foot is raised the blacksmith should never try to wrestle with the horse to hold the fot, but if a reasonable amount of force does not hold the foot, let go and confine them in such a manner as to oblige them to stand, so as not to strain or injure them; then be careful to cut all the clinches so as to pull off the shoe without wrenching the foot or allowing the clinches to lodge in the foot to cause lameness; then pear the foot on the bottom side on the toe until all the dead horn is gone, and nothing but good sound horn left; clean out all the dead horn from the bottom or sole, do not cut the frog only to cut off the loose particles, no matter if it does project below the shoe, it will do no harm, then with a rasp level the heel, leaving as much as possible; then the foot is ready to have the shoe fitted; never attempt to fit the shoe until the foot is peared. Then fit the shoe just the shape of the foot follow- 
ing t'se rim of the foot around to the frog. It is not necessary fo: the shoe to project any at the heel, either at the side or behind. Do not place the shoe on to the foot when hot to burn the foot as the steam that is generated by the heat will penetrate much farther than most persons would suppose, and injure the foot; but with a common rasp the foot may be leveled so that the shoe will rest all the way around alike. Never spring the heel to keep them from resting on the foot as that brings too much pressure in one place, and causes corns, or split hoof, or some other disease; drive the nails no farther up than is necessary to get a good substantial hold, as in driving them farther it cuts the hoof to pieces unnecessarily. Wide thin nails are the best, the nails should always be as thin as they can be driven so as not to press against the inner or sensitive part of the foot; and in finishing the foot do not rasp it above the nails, for in doing so the cuticle is destroyed and subjects the foot to injury in getting wet and dry, \&e. It is not best to have the shoe any heavier than is necessary to protect the foot, the calks should be no larger than is absolutely necessary, and if there are calks on the heel, there should be on the toe also, so as to keep the foot standing level; the calks should always lean a little from each other, so as not to hold dirt or snow; the toe callk should always project well forward, so that when the heel 
is raised the toe will still hold, and not slip to strain or discourage the horse. Horses that cut or interfere should have the inside of the foot raised and the outside lowered, either by pearing the foot or maling the shoe thickest on the inside; the object is to tip the ancles apart so as to give room for the foot to pass. It is not necessary to turn the calk or to bend the heel farther under the foot, as they cut with the side of the foot instead of the heel. For contracted feet, (See article on hoofbound.) For over-reaching or clicking, or cutting the forward feet with the hind shoe, sometimes the short shoe is best and sometimes the long one; the only way is to try first one and then the other. The whole science of shoeing consists in keeping the foot as near the natural form as possible, for when we attempt to force the foot trom nature's form we do an injury. 


\section{CHAPTER XIV.}

\section{INJURIES.}

\section{POLL-EVIL AND FISTULA.}

This is caused by some injury to the poll of the head, or to the wethers. When the poll is injured it may be done by hitting it on the upper portion of the stable, pulling at the halter, or knocking over the head with a club, or by tight reining. Fistula may be caused by a bad collar, or by bruising when rolling on the ground, by hitting it against a stick or stone. Poll-evil in the first stage, is a swelling on the top and back part, or poll of the head. That is hot and tender, and after a time matter accumulates, and forms in a sort of sack, then breaks and discharges; the muscles around then contract this sack until it is in an oblong form; then it is called a pipe. Fistula is the same thing only located on the wethers. When Poll-evil or Fistula first appears, examine it carefully with the hand, and if there is no soft place, then there is probably no matter formed, and it may be driven away. Make a sack of thin cloth large enough to cover the swelled place, and 
fill it with coarse salt, then moisten it with water, and pour on it $1 \mathrm{oz}$. of venus turpentine, and bind it on the swelled place at night, for two or three nights, moistering it with water every time before using, and if there is no matter accumulated it will drire it away. If on examining it there is a soft place, or you think that there is matter there, the sooner it is opened the better; take a seaton needle and put a piece of tape or some kind of string into it, and smear the string over with common fly blister salve, then put the needle down through the swelling, and draw the string in and leare it there; in putting the needle through put it in at the soft place and run it out as low down as possible; either tie the ends of the string together, or tie a stick into each end, so that it will not get pulled out; turn it once a day so as to keep the hole open. Let it remain a week or ten days; then pull it out and it will readily heal up, and needs no medicine. If it is already broke and discharging, it is then best to give the cleansing powders for a week or so, so as to get the system in a healthy condition; then wash the sore place off, and make some small sticks, a little smaller than a pipe stem, and use them for probes. Introduce one of the probes into each place that matter is discharging, and run them down as far as possible; that will show the depth and direction of the pipes, then take 
the roweling needle, as before directed, and intro. duce it by the side of the probe. The probe will serve as a director; and run it down to the bottom of the pipe; by measuring with the probe and marking it on the needle, you will know when you have got to the bottom. When at the bottom take the probe out and guide the needle out as low down as possible, and fix the string as lefore directed. There must be one through each pipe. Let the string remain ten days, or until the matter that discharges becomes bloody; then take it out and it will heal without medicire. It is best always to use the rowels if possible. Sometimes the pipes run in such a direction that it would not be possible to use the rowels; if such is the case take some nitrate of silver and pulverize it finely, and add three times as much flour, take the probe, wet it, dip it into the powder and push it into the pipe, and repeat this until the pipes are all filled, and leave it for three days; then with a syringe and soap and water clean it all out nicely, and be very sure to keep it clean by washing it out three or four times per day, and each time after washing inject enough of the following to wet it nicely: chloride of zinc 2 grains, to $1 \mathrm{oz}$. water, and continue this until it is $\mathrm{h}$ aled up. If it does not heal up it is because the pipes are not all destroyed, and the powdered nitrate of silver will have to be used again, as before direc- 
ted. If it is an old standing case, or the disease seems to be deep seated, or should you fail with the above treatment, then the only chance is to cast the horse and cut it open, and take out all the diseased parts, and treat it then as any fresh wound. The chloride of zinc wash is the best to heal it, as it will prevent proud flesh, 1 grain to the oz. of water. In treating poil-evil and fistula it is of the utmost importance to keep it clean, and the horse should be kept in a stable, as in running at grass and holding the head down, it makes it worse, and almost impossible to cure; and after it is cured the horse should not be turned out for six months, as holding the head down might bring it on again. It is also necessary to be very careful to not let the harness rest on the place where it has been cured, as the place will remain tender for a long time, and there is great danger of inducing it to break again.

\section{INFLAMIATION OF THE VEIN AETER BLEEDING.}

It is scarcely necessary to mention a disease of this kind, as it is so seldom met with; but in years gone by, when it was a common thing to bleed for most any trifling complaint, it was very common. The first appearance of this disease is that the eages of the wound will spread apart, and there will ooze out a thin, watery fluid; then a 
small lump will appear, and perhaps several of them along the course of the vein. These will perhaps break and become running sores, and in the end, the vein will be destroyed, and the smaller blood vessels will have to perform the office of the one destroyed. In the first stages of this disease, the treatment must be in repeated blistering; and as often as one blister has healed, apply another on the affected part. If the lumps break and become running sores, then, with a

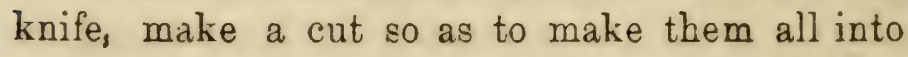
one; that is, run the cut from one to the other, so as to let them all open, and treat the same as any fresh wound.

\section{FISTULIOUS PARATOII DUCT.}

There is, on the inside of the cheek, a duct or pipe that conveys the saliva from the glands into the mouth when the horse is eating. Sometimes, the mouth of this duct gets closed by getting hay seed, or some foreign substance into it, or there may be a calculus, or lining enlargement that closed the duct, and as the horse eats, the rnovement of the jaw causes the glands to pour forth the saliva into the duct, and that being closed, it breaks through the cheek and makes an unnatural opening where the saliva will squirt out when the horse moves the jaw. This is not a very common complaint, and it is well it is not, as it is 
very difficult to cure. The plan is to first cut the edges of the opening so as to make them raw, and as soon as the bleeding is stopped, take a good sticking plaster, cut into strips, and draw the skin so as to bring the edges together and put the plaster on so as to hold it together; and it is well to put several of them on, one over the other, for the principle is to keep the edges together until they heal. If you fail the first time, try again, until you succeed in keeping them together.

\section{BROKEN KNEE.}

This is usually caused by a fall, or hitting against some hard substance, and is usually of much more importance than most of horse owners are aware. Any bruise of the knee joint should be attended to immediately, or the worst consequences may follow. This injury is usually on the forward limb; and if the skin is not broken, salt and water, or tincture of arnica, $2 \mathrm{oz}$. in a quart of water, applied every half hour by merely wetting the part; and be sure to keep it. wet until there is no appearance of inflammation. But if the skin is broken and loose below the wound, make a hole through the skin at the lowest part that it is loose, so that there may be a free discharge below; then wash the wound off by pouring water on it. Do not rub it with a 
sponge or your hands. Then keep it wet as above directed, until the matter begins to discharge, and be careful to keep the hole open below, and do not put any bandages on. 'Then, instead of the above wash, use the chlorade of zinc, say 1 grain to the oz. of water. Use this by merely pouring it on so as to wet the place, four or five times per day. The above treatment is all that is required, with any injury to the joints, even though the joint oil may discharge. This treatment, properly applied, will stop it in a few days.

\section{WOUNDS.}

Wounds are of so many different kinds and locations that it would hardly be possible to describe them all, so I will only give the general principles. If a wound has cut any of the blood vessels, and they are of any size, they will have to be taken up. This is done by catching hold of them with a small, sharp hook, and tieing a piece of white silk thread around them. If the wound is of much size, it must be serred up; and be careful to take the stitches deep into the skin, so that they will not break out in a few days. A white silk cord, thoroughly waxed with beeswax, is best, and make each stitch separate; that is, tie each stitch, so that if one breaks out it will not involve the balance. If the wound is small and deep, then the hole should be made longer 
by cutting, so as to be sure to give a free discharge. Then keep them wet with salt and water, or tincture of arnica, $4 \mathrm{oz}$. to one quart of water, until it begins to matterate; then use the chloride of zinc wash, say 1 grain to the oz. of water, four or five times per day; and if proud or fungoid flesh should get into the wound, use the healing wash for old sores. It is best to never bandage a wound on a horse if it is possible to get along without it, as the bandage chafes it and creates inflammation.

\section{STRAINS OR SPRAINS.}

Whenever a horse sprains, strains or bruises any part, it should not be neglected, as it may result in something very serious. I believe that two-thirds of the blemishes that we so often see, that are caused by strains and bruises, might be avoided if attended to on the start. Many times, when a cord, or tendon, or ligament is strained or bruised, there will be no serious symptoms for several days. Then it will take an inflammation of a serious character; and when these organs. once become diseased they are very difficult to manage. Neglect in a case of this kind is dangerous indeed. The principle to be adopted in all cases of strains, bruises, or injuries of this kind is to subdue inflammation. This can always. be done by keeping the part constantly wet with 
anything that is cooling. For instance, salt and water, tincture of arnica and water, or any cooling application, but it must be kept on cold all the time, and if by neglect or inattention, matter accumulates, then the place should be opened, always being careful to open in such a position that there can be a free discharge, and then use the wash as above directed.

\section{OPERATIONS.}

\section{NERVATOMY.}

This is dividing the nerve of the forward leg, just above the ankle, to dertroy the sense of feeling to the foot, and is highly recommended by some of the English authors for certain diseases of the foot, but in this country, it has got into disrepute, because it has been indiscriminately practiced by men that either did not know the consequence, or did not care; and the result was, that in most cases, borses that have been nerved have lost their feet by sloughing off. But for all this, no doubt it is a humane operation, and results in much benefit when judiciously applied, in rertain cases.

\section{TREACHOOTARY}

- Consists in making a hole through the wind-pipe, about fourteen inches below the jaw, and inserting a tube about one inch in thickness, for 
the horse to breathe through in cases where they are liable to strangle by some throat disease, and let it remain until the disease is cured, then remove the tube and let it heal.

\section{ROWELING.}

This is done by threading a piece of tape into a seton needle, and putting the needle through the skin, and draw the tape in and let it remain, either tying the ends together or tying small sticks into each end to prevent it from getting pulled out, and to put something on to the tape to create a discharge. I generally use common fly blister salve. All rowels should be pulled through every day so as to keep the hole open. Rowels are used many times in cases of inflammation of the eyes. Then they are put into the cheek, three or four inches below the eye. They are used in most cases of blood diseases. Then they are put into the breast, and I generally, in cases of this kind, put in at least two. In water farcy, they are put into the swelled part. In the poll evil and fistula, they are put down through the pipes. They are frequently used in swellings and callouses, and whenever they are used they should be allowed to remain as long as they discharge freely; and in some cases, it is best to put more blister salve on the string and draw it in, to renew the discharge. When it begins to 
dry up, and it is thought best to take them out, merely cut the string and pull them out, and it will heal up itself, and will not need medicine.

\section{DOCKING}

Is cutting off the tail, and it is done whenever it is wished to make a bob-tail. Many times, horses have very long and heavy tails, so that they do not carry up, and by cutting a piece off the tail it will improve them; and it is also done when the tail is crooked near the end. It is done by first parting the hair nice and even at the place where you wish to cut, and tying the hair that is designed to leave on the tail, back out of the way, then lay a block on the top of the hips, and stand by the side of the horse; draw the tail up over the back until it rests on the block in the right position, and let an assistant stand on the other side of the horse and hold it there; then place some sharp instrument, like a chisel, on it, and with a blow from a mallet, or hammer, cut it off. Be sure to cut it at one blow. Then let it bleed a few minutes, and bind on the end a small bunch of hog manure, or horse manure, and pull the hair down over it, and tie it in such a manner as to keep the manure tight up against the end of the tail, and that will stop the bleeding. Let it remain for twenty-four hours, then take it off and wash the tail clean, and it will 


\section{3}

heal without difficuity, and leave scarcely any bald place. Do not burn the end of the tail, or cord it tight to stop the bleeding, as that will cause the hair near the end to drop out and leave too large a bald place.

\section{PIICKING OR NICKING.}

Nicking is to take a piece of the cord of the tail out, so as to make the tail stationarily erect. This is an old-fashioned practice, and is not used now. Pricking is merely to separate the cords on the lower corners of the tail, so as to allow the tail to be raised higher than it otherwise would be. The tail may be cut off so as to make a bob-tail or not, according to fancy. To prick a horse, place him in stocks or fasten them so they cannot kisk the operator. Stand behind the horse and grasp the tail with the left hand and raise it so it will be straight up, and with the right hand, insert a knife a little up on one side, near to the edge of the hair, and about one inch from the body, and push the blade towards the center of the bottom of the tail until it reaches nearly to the center, but do not push it clear out. Then turn the edge of the knife towards you and cut until you feel the edge of the knife against the skin with the thumb, or until the cord is cut entirely off. Then change hands, and with the left hand, cut the other side in the same manner. Once cutting on each side 
will be enough, if it is only wished to raise the tail without cutting it off, or if it is wished to have it straight from the body out; but if it is wished to have a half jockey tail, or to have it a little curved up, then cut again on both sides, about two inches farther out; and if it is wished to have a full jockey tail, or to curve well up, then make still another cut on each side, about one and a half inches farther out towards the end. If it is merely wished to raise the tail, it is not necessary to put the horse in pulleys, but every day give the tail a sudden and hard pull up over the back for three or four weeks; but if it is desired to make a bob-tail, then stand the horse in a narrow stall, and attach a pulley to the upper floor, on each side, so that they will be about opposite the horse's hips. They should be attached by strings so as to allow them to turn either way; then attach a cord in the center to the hair on the end of the tail, and let each end of the cord run up over the pulleys and down to the floor, and attach just enough weight to each end of the cord to pull the tail up a little higher than it is wished to have it when it is done. Give the horse some feed when he is first put in the pulleys so as to attract his attention until he gets used to them; and it is necessary to keep him standing in a position to keep the tail straight all the time he remains in the pulleys. After the first 


\section{5}

night, he will lay down and make himself comfortable, and they generally gain in flesh faster while in the pulleys than at any other time. The next day after the pricking take him out and wash the tail clean, and move the horse gently for about fifteen minutes, then put him back, and do so every day for four or five days; if the tail gets hot and feverish keep it wet with salt and water so as not to loosen the hair. In about a week cut the tail off, (See Docking,) leaving the length about one inch for every hundred pounds weight of the horse, then pully again but be sareful to not use any of the hairs at the end of the tail, but use the hairs that are farther back, and keep the horse in the pulley for two weeks steady, then afterwards keep him in when not at work for two weeks longer.

\section{CROOKED TAILS.}

Many horses carry their tails to one side, which is considered by most horse men as a serious defect; this may be remedied by cutting the cord on the side that the tail crooks to, the same as pricking. (See pricking and nicking.) The cut must be made about the point where the crook is and only cut on one side. Sometimes it is necessary to cut it in two, and, even then place as the judgment of the operator may decide; then the tail should be kept tied around to the collar on 
the opposite side when the horse is not at work for three weeks, so as to keep the ends of the cords apart until the vacant place fills up so as to lengthen the cord on that side.

\section{BLEEDING.}

The practice of bleeding horses for every diffculty that used to be so common, and I am sorry to say is still practiced by some professional horse doctors, $\mathrm{I}$ believe is abandoned by practitioners on the human subject, and why not abandon it on horses, for every thinking man must acknowledge that blood is never drawn from the system without injury; but there are some cases where the symptoms are so urgent that we have to bleed to give temporary relief, even though it does injury in the end ; and above all the practice of bleeding in the mouth I consider most cruel and barbarious. What would be thought of the physician that would bleed his patients in the mouth. I believe that some claim there are great results from allowing a horse to swallow the blood when bled in the mouth; even was this so, would it not be better to draw it from the vein and drench with it, then the practitioner would know how large a dose he was giving. The most convenient place to bleed is in the jugular or neck vein, place a cord around the neck near to the body and draw it tight, and the vein will fill with blood so that it may be 


\section{7}

plainly seen, then place the fleam on and with a suitable stick knock it in and the blood will spout forth, or it may be done with a lance or common knife. Take the blade between the thumb and fore finger allowing enough of the blade to project to penetrate the vein so that the thumb and finger will form a guard, and not allow the blade to enter too far, and always make the cut lengthways of the vein. The vein may be penetrated wherever it shows itself the most plain. As soon as you have got blood enough slack on the cord and it will almost stop bleeding; then stick a pin through the edges of the skin and draw them together, and pull a little hair out of the mane and wind it around; pull it out in twenty-four hours afterwards. Sometimes it is necessary to bleed below the eye in acute inflammation of the eye ; place the thumb of the left hand across the face about two inches below the eye and press on to it, and the vein will show itself above; then with any sharp pointed knife open the vein, and a very little blood will answer, and it will not be necessary to pin up the hole as it rarely ever bleeds enough to do injury; but bleeding below the eye is simply temporary relief consequently it is necessary to proceed at once with medicine for the eye.

\section{SURGICAL OPERATIONS.}

It will be impossible to describe the different surgical operations that are necessary some times; 
but a few plain words of advice will perhaps not be out of the way. Before attempting even the smallest surgical operation, the operator should have a correct knowledge of the parts where he is going to operate, as there are sometimes serious results from cutting that is done by the hand of the ignorant. To make any surgical operation, contemplate well the part where you are going to operate, and make up your mind before commencing just where you are going to cut, and how much you are to cut, and always be careful to accomplish as much at one cut as possible. Draw the knife smoothly, so as not to mangle; be sure that the patient is well secured before commencing, also be cure that every thing is at hand that may be wanted-water, sponge, needles, cord, knife, a hook to take up the blood-vessels, and caustic to stop the bleeding, and all necessary dressings to dress the wound. In sewing up a wound make each stitch by itself; that is, tie each stitch before making another, so that should one stitch break it would not affect the next. Never cut out any of the loose skin where you have taken out a tumor, as it will eventually all shrink down and leave the less scar. The operator should always allow the assistants to confine or cast the horse under his direction, so as to keep his nerves calm. Always be sure that there is as little noise and confusion as possible when cutting. Should the 
horse struggle, wait until the struggles cease. If there is any skin to be kept out of the way, put a cord through it with a needle, and allow one of the assistants to hold it; and also if there is a tumor being cut out, put one in for the operator to hold on to and turn in either direction, as the case may require. The operator should never be governed by what the bystanders may say, but be careful and keep himself free from excitement, and work with a bold and firm hand, and good common sense will direct nearly everything that is to be done.

DISLOCATED JOINTS AND BROKEN LIMBS.

It will hardly be possible to give any correct knowledge on this part of the subject, without the reader has a correct knowledge of Anatomy, but still some plain directions will not be out of place, as it is not always possible to obtain the services of a veterinary surgeon. Happily dislocated joints are not very common with horses. After a joint is dislocated the sooner it is put into place the easier it can be done. The directions here given for dislocated joints will answer equally as well for broken limbs. If the joint has become so badly swollen that you cannot feel the joint plainly, then go to work with warm hop tea and keep bathing the part until you get the swelling enough reduced to operate. I will hear relate a 
case that I once treated which will serve as a guide. A fine four year old stallion dislocated his ankle so that the foot turned almost up by the side of the leg; the owner was about to destroy the horse, but finally concluded to send for me. When I arrived, after examining the limb, I ordered one the assistants to bathe the joint with tincture of lobelia and warm water, to relax the parts, and to continue the batning for half an hour. I then ordered a bandage to be prepared of good stout cloth, about two and a half inches wide and five or six yards long, and to have it starched with good flour starch. I then rolled it up into a small bunch and prepared some splints about eight inches long and one inch wide, and then I ordered the horse to be cast, which was soon done, and the well legs well fastened together. I put a long strap around the foot of the limb that I was to operate on, and had one of the assistants take hold of it and pull straight out, commencing gently at first, and increasing the force unil it was sufficiently extended, and then with my hands I crowded the bones into place, and allowed one of the attendents to support the limb while I bound the bandage on by putting it round and round, and drawing it tighter every time; after I had wound it several times around I placed the splints on and bound the bandage over them and pinned the end. I then allowed 
the horse to rise, the rext day he could bear a little heft on the toe. I let the bandage remain one week, then removed it and applied a bandage of flannel cloth, and allowed him to wear that one week ; and in three weeks after I set the joint the horse was driven to a buggy and run away without injuring the joint.

The above will I think be sufficient to instruct how to manage most of cases of this kind. Good common sense will direct most any person how to manage a broken or dislocated limb.

\section{HOW TO GIVE MEDICINES.}

Some kind of medicines may be given by putting it into the food or arink, but more frequently it has to be given in a drench or pills. Never drench a horse through the nose as it is dangerous. When you want to drench a horse, put a bridle on to him and allow an assistant to get up over head in the barn and draw the head up, and be sure to get it well up; do not pull the tongue out for the horse needs the use of it in swallowing; then with a long necked bottle or horn, pour enough into the mouth for one swallow, and if the horse does not readily swallow it, wait and give bim time; and if that does not do, place the hand over the nostrils and stop the breathing for a moment, and as you let go, give the head a sudden start or push, and whatever there is in the 
mouth will go down. Never pound the throat or halloo at the horse, but take time enough and get it down without injury, or abusing the sick horse. To give pills get a stick like a whip stalk, and cut a notch in the end, cover the pill with very thin paper and grease it with some soft oil; put it on the end of the stick; let the assistant raise the head and pull the tongue out at one side; you then grasp the lip on the upper jaw to assist in keeping the mouth open, and to steady the head, then put the pill as far back on the tongue as possible, and turn the stick so that it will drop off, and let go the tongue, and it will go down. 


\section{CHAPTER XV. RECEIPTS.}

\section{SPAVIN AND RINGBONE MEDICINE.}

This medicine is to be used for any case of ringbone or spavin. It is good for windgalls, thickened glands, and old callouses. Apply as for windgalls. Take of cantharides, $20 \mathrm{z}$, mercurial ointment, 4 oz., corrosive sublimate, 3 drams, turpentine, 3 oz., tincture of iodine, 2 oz., ellphrobium, 1 oz.; mix well with 2 lbs. of lard. If for ringbone or bone-spavin, cut off the hair from the part affected, and merely grease the lump with the ointment, rubbing it well in with the hand. In two days, grease the part with lard, and in four days, wash it off with water and soap and apply the ointment again, and repeat it. every four days. If for windgalls, bog-spavin, curbs, splints, enlarged glands, or any unnatural growths, lumps, or callouses, apply only every six days.

HOW TO MAKE DROPS TO MAKE OLD HORSES YOUNG.

Take tincture of asafotida, 1 oz., tincture cantharides, 1 oz, antimony, $2 \mathrm{oz}$., fennegreak, $1 \mathrm{oz}$. 
fourth proof brandy, $\frac{1}{2}$ gallon; let it stand 10 or 12 days, and give ten drops in a pail of water of one gallon.

NERVE AND BONE LINIMENT.

One oz. spirits of turpentine, $\frac{1}{2}$ oz. oil arganum, $1 \mathrm{oz}$. oil spike, 1 oz. British oil, 1 oz. tinc. of myrrh, $2 \mathrm{oz}$. compound tinc. of myrrh or tinc. of capsicum, 2 oz. tincture camphor. For any old chron. ic complaint, add $1 \mathrm{oz}$. tincture of cantharides.I have used this liniment for over fifteen years on man and beast, for strains, bruises, cuts, burns, and particularly rheumatism. It will pay every one to keep some of it on hand.

\section{CLEANSING HOWDERS.}

These are good for all cases where the blood is out of order, such as farcy, yellow water, grease heel, indigestion, worms, loss of appetite. They are to be used as a general cleansing condition or regulating medicine, and wherever it is used it is highly spoken of. Take $4 \mathrm{oz}$. powder gentian, $4 \mathrm{oz}$. pulverized blood root, 4 oz. golden seal, $1 \frac{1}{2}$ oz. nitre, $\frac{1}{2}$ oz. crude antimony, $\frac{1}{2}$ oz. calomel ; mix all well together, and give one large spoonful at a dose, in wet food. They are perfectly safe. If the horse is troubled with worms or yellow water, add $\frac{1}{2}$ oz. more calomel. 
IODINE OINTMENT, EXCELLENT FOR MIAN OR BEAST.

For rheumatism, sprains, burns, swellings, bruises, or any inflammation on man or beast; chapped hands or lips, black eyes, or any kind of bruises. Take fresh butter, 2 lbs., tincture of iodine, 3 oz., oil arganum, 2 oz. Mix these well together for fifteen minutes, and it is fit for use. Apply every night and rub in well with the hands. If for human flesh, lay on with flannel.

\section{LINIMENT FOR SWELLINGS.}

Take linseed oil, $\frac{1}{2}$ pint, tincture iodine, $3 \mathrm{oz}$, turpentine, 4 oz., oil of arganum, 1 oz.; shake well and apply it every day; rub it well with your hand; wash the part well with soap and water before applying it. This is good for any swelling.

LINIMENTS FOR CONTRACTED TENDONS OF THE NECK, OR ANY CONTRACTED TENDONS OR CORDS.

One pint of sweet oil, 1 oz. gum camphor, 1 oz. tincture of opium. Apply and rub the part well with the hand.

\section{HEALING WASH FOR OLD SORES.}

Four oz. pulverized blood root, 1 oz. camphor gum, $6 \mathrm{oz}$. tincture of arnica, and add enough alcohol to make one quart. Shake it well, then let it settle and it is fit for use. 


\section{CONTENTS.}

\section{CHAPTER I.}

PAGR.

DISEASES OP THE BRAIN, .......... 12

Inflammation of the Brain-Blind Staggers-Hydrophobia or Madness-Tetanis or Lock Jaw-Paralysis, Partial or Complete.

\section{CHAPTER II.}

DISEASES OF THE EYE,............. 18

\section{CHAPTER III.}

THE MOUTH,

Lampers-Canker or Sore Mouth.

\section{CHAPTER IV.}

THE NOSTRILS,

Nasal Polypus.

\section{CHAPTER V.}

THE THROAT, ........................ 24

Sore Throat-Cough-Choking.

CHAPTER VI.

THE CHEST, ITS DISEASES, ............ $28^{*}$

Lung Fever-Dropsy of the Chest-Heart Disease. 


\section{CHAPTER VII.}

DISEASES OF THE STOMACH, ......... 34 Inflammation of the Stomach-Chrouic Inflammation of the Stomach-Crib Biting-Bots.

\section{CHAPTER VIII.}

THE BOWELS, ................... 42 Spasmodic Colic-Windy Colic-Inflammation of the Bowels-Acute Dysentery-Chronic Dysentery-WormsInfluenza.

\section{CHAPTER IX.}

DISEASES OH THE URINARY ORGANS, . . . . . 51. Inflammation of the Kidneys-Inflammation of the Bladder -Stoppage of the Water-Stone in the Bladder-Bloody Urine-Diabetes, or too free a discharge of the Water.

\section{CHAPTER $X$.}

DISEASES OF THE SKIN, . . . . . . . . 56 Mange-Ring Worm-Surfeit-Lice-Larra, or Grubs in the Skin-Warts-Tumors-Swelled or Stocked LegsSitfast - Grease Heel-Malanders and Sallanders Scratches or Cracked Heel.

\section{CHAPTEK XI.}

SPECIFIC DISEASES,

Heares or Wind Broken-Mellanoises-Water Farcy-Purpura Hemorrhagica-Distemper or Strangles-GlandersButton Farcy-Yellow Water.

\section{CHAPTER XII.}

DISEASES OF THE LIMBS, ............. 74 Bone Sparin-Splint - Ringbone-Curb-Bog Sparin and Thoroughpin-Stringhalt-Shoulder Jam and sweenyCapped Knee-Capped Hock-Capped Elbow-The Stifle -Blood Spavin.

\section{CHAPTER XIII.}

DISEASES AND ACCIDENTS OF THE FEET, .. . 88 Cracked Hoof-False Quarter-Seedy Toc-Calked Tread and 0 rer-reaching-Corns in the Feet-Quitter-Thrush or Canker of the Foot-Founder-Coffin Joint Lameness -Hoof Bound and Contracted Feet-Shoeing. 


\section{CHAPTER XIV.}

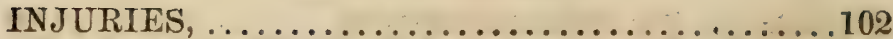

Poll-Evil and Fistula-Inflammation of the Veins after Bleeding-Fistulious Paratoid Duct-Broken KneeWounds-Strains or Sprains-Operations-NerratomyTreachootary-Roweling-Docking-Pricking or Nicking -Crooked Tail-Bleeding-Surgical Operations-Dislocated Joints-How to give Medicine.

\section{CHAPTER XV.}

RECEIPTS,

Spavin and Ringbone Medicine-How to make the Drops to make the old horse young-Nerve and Bone LinimentCleansing Powders-Iodine Ointment-Liniment for Swellings-Liniment for Contracted Tendons of the Neck -Healing Wash for old sores. 





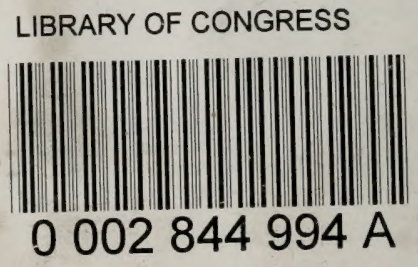

